\title{
Unexpected coelenterazine degradation products of Beroe abyssicola photoprotein photoinactivation
}

\author{
Ludmila P. Burakova, Maria S. Lyakhovich, Konstantin S. Mineev, Valentin N. Petushkov, \\ Renata I. Zagitova, Aleksandra S. Tsarkova, Sergey I. Kovalchuk, llia V. Yampolsky, Eugene S. Vysotski, \\ Zinaida M. Kaskova
}

\section{Contents}

Materials and Methods

Extraction and purification procedures

Spectral properties of isolated compounds

Synthesis and purification of synthetic compounds

$1 \mathrm{H}$ and 13C NMR of the synthesized compounds 
Chemicals and synthesis. Coelenterazine was obtained from NanoLight Technology, a division of Prolume Ltd. (Pinetop, USA). A stock coelenterazine solution was prepared by dissolving in methanol and stored at $-20^{\circ} \mathrm{C}$ for several days. Concentration was calculated by absorption at $435 \mathrm{~nm}$ using the $\varepsilon_{435 \mathrm{~nm}}=$ $9800 \mathrm{~cm}^{-1} \mathrm{M}^{-1}$. Other chemicals, unless otherwise stated, were from Sigma-Aldrich (St. Louis, MO, USA) and the purest grade available. Merck Kieselgel 60 was used for column chromatography. Thin layer chromatography was performed on silica gel 60 F254 glass-backed plates (Merck), solvent systems: $\mathrm{CH}_{2} \mathrm{Cl}_{2}$ or $\mathrm{CHCl}_{3}-\mathrm{EtOH}-\mathrm{AcOH}$ 90:9:1. Visualization was effected by UV light (254 or $365 \mathrm{~nm}$ ) and staining with vanillin, $\mathrm{FeCl}_{3}$ or $\mathrm{KMnO}_{4}$ solutions.

UV-Vis and fluorescence spectra measurements. The absorption and fluorescence spectra were recorded with a double-beam scanning spectrophotometer UV 2600 (Shimadzu, Japan) and Cary Eclipse fluorescence spectrophotometer (Varian, USA), respectively, in a $1.0 \mathrm{~cm}$ quartz cuvette. The measurements were performed in $50 \%$ acetonitrile and $0.05 \%$ formic acid water solution at room temperature. Fluorescence spectra were corrected for spectral sensitivity of the detector with a computer program supplied with the instrument.

HRMS analysis. High-resolution mass spectra of natural compounds were registered on Agilent 6224 TOF LC/MS System, equipped with a dual-nebulizer ESI source, analysis of mass-spectra was performed on MassHunter Workstation software (Agilent Technologies, Santa Clara, CA, USA). High-resolution mass-spectra of synthetic compounds were obtained on QExactive Plus Orbitrap mass-spectrometer (ThermoScientific, USA). Samples were injected directly into the ESI ion source by a syringe in the solution of $0.1 \% \mathrm{FA} / 90 \%$ acetonitrile/10\% $\mathrm{HO}$. MS data were collected in DDA mode with the spectra recorded in Positive and Negative modes with 150-2000 mass range at 70K resolution for MS1 and $17.5 \mathrm{~K}$ resolution at $30(\mathrm{~N}) \mathrm{CE}$ and $1.4 \mathrm{~m} / \mathrm{z}$ isolation window for MS2.

NMR analysis. NMR spectra of natural compounds were acquired in $d_{4}-\mathrm{CH}_{3} \mathrm{OH}$ (Sigma Aldrich, Germany) at $30^{\circ} \mathrm{C}$ on the $600 \mathrm{MHz}$ Avance III Bruker NMR spectrometer (Bruker Biospin, Germany), equipped with the cryogenic triple resonance probe. In case of the fractions $A B 2$ and $A B 3$, a full set of NMR experiments was recorded, including the ${ }^{13} \mathrm{C}-\mathrm{HSQC}$, DQF-COSY, ${ }^{13} \mathrm{C}$ and ${ }^{15} \mathrm{~N}$ HMBC. For individual samples of PB1, PB2, PB3 only the DQF-COSY and $1 \mathrm{H}$ spectra were recorded, while for the unified sample of PB1 and PB3, the DQF-COSY, ${ }^{13} \mathrm{C}-\mathrm{HSQC}$ and ${ }^{13} \mathrm{C}-\mathrm{HMBC}$ (optimized for $8 \mathrm{~Hz}, 18 \mathrm{~h}$ ) spectra were obtained. NMR spectra of synthetic compounds were acquired in $d_{4}-\mathrm{CH}_{3} \mathrm{OH}, d_{6}-\mathrm{DMSO}, \mathrm{CDCl}_{3}$ (Eurisotop, France) at $30^{\circ} \mathrm{C}$ with $\mathrm{Me}_{4} \mathrm{Si}$ as an internal standard on the Bruker Fourier $300 \mathrm{MHz}$ and Avance III Bruker $600 \mathrm{MHz}, 700$ $\mathrm{MHz}$ and $800 \mathrm{MHz}$ spectrometers. 


\section{Extraction and purification procedures}

Expression, purification, and photoinactivation of recombinant berovin: For apophotoprotein production, the E. coli BL21-Gold (DE3) Codon Plus (RIPL) cells transformed by plasmids carrying berovin ${ }^{1}$ or aequorin ${ }^{2}$ were cultivated with vigorous shaking at $37{ }^{\circ} \mathrm{C}$ in LB medium containing ampicillin $\left(200 \mu \mathrm{g} \mathrm{mL}^{-1}\right)$. Protein expression was induced with $1 \mathrm{~mm} \mathrm{IPTG}$ at $\mathrm{OD}_{590} 0.6-0.8$ and the cultivation was continued for another $3 \mathrm{~h}$. Berovin and aequorin were purified and charged with coelenterazine as described elsewhere ${ }^{3}$. Active photoproteins were separated from apoproteins and coelenterazine excess by chromatography on a HiTrap Q HP 5 column (GE Healthcare) and were of high purity according to SDS-PAGE analysis. The bioluminescence of berovin and aequorin was measured by rapid injection of 10 $\mu \mathrm{L}$ photoprotein solution in $5 \mathrm{~mm}$ EDTA, $20 \mathrm{~mm}$ Tris- $\mathrm{HCl}$ pH 7.2 into a luminometer cell containing $490 \mu \mathrm{L}$ of $2 \mathrm{~mm} \mathrm{CaCl}$ in $50 \mathrm{~mm}$ Tris- $\mathrm{HCl} \mathrm{pH} 8.5$ at room temperature. Photoinactivation of berovin was carried out at $0^{\circ} \mathrm{C}$ (on ice) with an incandescent lamp by placing a $1 \mathrm{~mL}$ sample of berovin into a $1.5 \mathrm{~mL}$ Eppendorf-type tube about $20 \mathrm{~cm}$ away from the light source. Photoinactivation was controlled by the measurement of the residual bioluminescence activity. $\mathrm{Ca}^{2+}$-discharged berovin was prepared in the dark by adding $50 \mathrm{~mL}$ of $100 \mathrm{~mm} \mathrm{CaCl}_{2}$ in $50 \mathrm{~mm}$ Tris- $\mathrm{HCl} \mathrm{pH} 8.5$ to $1.5-\mathrm{mL}$ sample of high purity active berovin $\left(1.2 \mathrm{mg} \mathrm{mL}^{-1}\right)$ after chromatography on HiTrap Q HP 5 column. When bioluminescence ceased, the solution was used to extract the reaction products.

Extraction and purification of compounds from proteins: To extract compounds bound within photoprotein, the sample in water solution was loaded on the C16 column (Diapack 16, BioChemMak, Moscow, Russia) and then the column was washed with $5 \%$ acetonitrile water solution. At this purification step protein was removed from the sample. The low molecular weight compounds were eluted by $90 \%$ acetonitrile water solution. The sample was then dried by vacuum Concentrator 5301 (Eppendorf, USA) at room temperature, diluted in $50 \%$ acetonitrile aquatic solution, and subjected to preparative RP-HPLC (C18 $0.9 \times 25 \mathrm{~cm}$ (Agilent Technologies, USA) column, formic acid/acetonitrile $=0.1 / 99.9$, flow rate $=3.0$ $\mathrm{mL} / \mathrm{min}, \lambda=330 \& 360 \mathrm{~nm}$ ) $\mathrm{tR}=14.2 \mathrm{~min}$ (major), $15.6 \mathrm{~min}$ (minor). The extraction and purification procedures were the same for all photoprotein samples with one exception-extraction of low molecular weight compound from active berovin was performed at red light to prevent its photoinactivation.

\footnotetext{
${ }^{1}$ GenBank Accession No. JN673815

2 GenBank Accession No. AAA27716.

3 (a) S. V. Markova, L. P. Burakova, S. Golz, N. P. Malikova, L. A. Frank, E. S. Vysotski, FEBS J. 2012, 279, 856-870. (b) B.A. Illarionov, L.A. Frank, V.A. Illarionova, V.S. Bondar, E.S. Vysotski, J.R. Blinks, Methods Enzymol., 2000, 305, 223-249. (c) E.S. Vysotski, Z.J. Liu, J. Rose, B.C. Wang and J. Lee, Acta Crystallogr. D Biol. Crystallogr., 2001, 57, 1919-1921.
} 


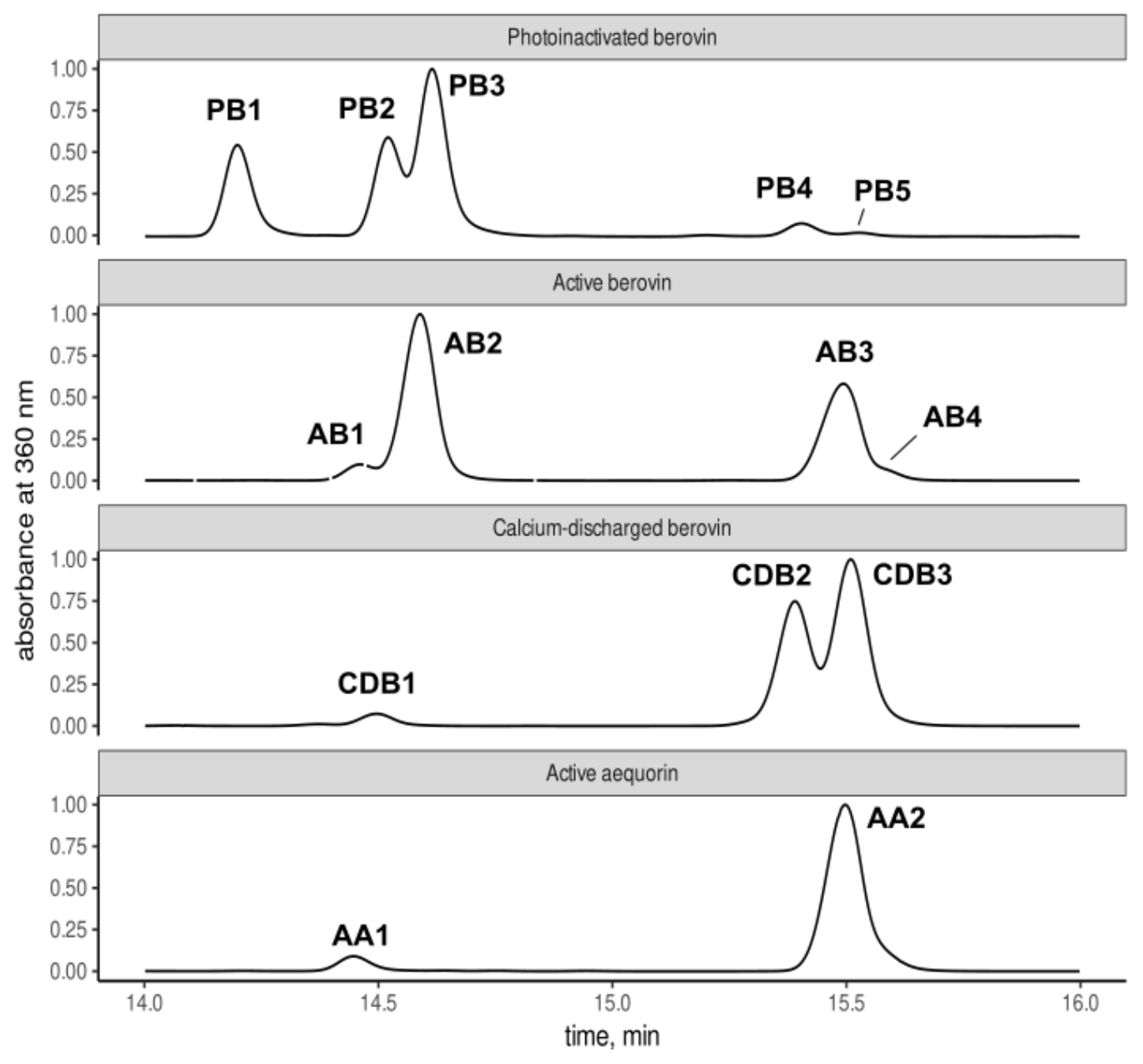

Figure S1. RP-HPLC traces for compounds extracted from photoinactivated (PB), active (AB) and $\mathrm{Ca}^{2+}$-discharged (CDB) berovin, and active aequorin (AA) at $360 \mathrm{~nm}$. Major fractions from photoinactivated berovin are PB1-PB3, minor - PB4, PB5.

BL testing of fractions with Gaussia luciferase. Recombinant luciferase of high purity from copepod Gaussia princeps was produced in insect cells as described ${ }^{4}$. To test the extracted compounds as bioluminescent substrates, $2 \mu \mathrm{L}$ of a compound in $50 \%$ acetonitrile and $0.05 \%$ formic acid was injected into luminometer cell containing $493 \mu \mathrm{L}$ buffer $(25 \mathrm{mM} \mathrm{NaCl}, 1 \mathrm{mM}$ EDTA, $50 \mathrm{mM}$ Tris- $\mathrm{HCl} \mathrm{pH} 7.0)$ and 5 $\mu \mathrm{L}$ of the luciferase. The assays were performed at $23^{\circ} \mathrm{C}$. Coelenterazine in the same solution was used as a control. None of the tested substances revealed bioluminescence whereas the light signal with coelenterazine at the same conditions was very high.

Repeated HPLC for fractions PB1 and PB3. The compounds were rechromatographed by HPLC (C18 $0.9 \times 25 \mathrm{~cm}$ (Agilent Technologies, USA) column, formic acid/acetonitrile $=0.1 / 99.9$, flow rate $=3.0$ $\mathrm{mL} / \mathrm{min}, \lambda=330 \& 360 \mathrm{~nm}$ ), $\mathrm{tR}=14.2 \mathrm{~min}$ (major), $14.6 \mathrm{~min}$ (minor).

As a result of the chromatography of isolated PB1 or PB3 on the C18 column we always observed the elution of two compounds with retention time corresponding to time for PB1 and PB3. Thus it was suggested that PB1 and PB3 are isomers.

\footnotetext{
${ }^{4}$ M.D. Larionova, S.V. Markova, E.S. Vysotski, J. Photochem. Photobiol. B., 2018, 183, 309-317.
} 


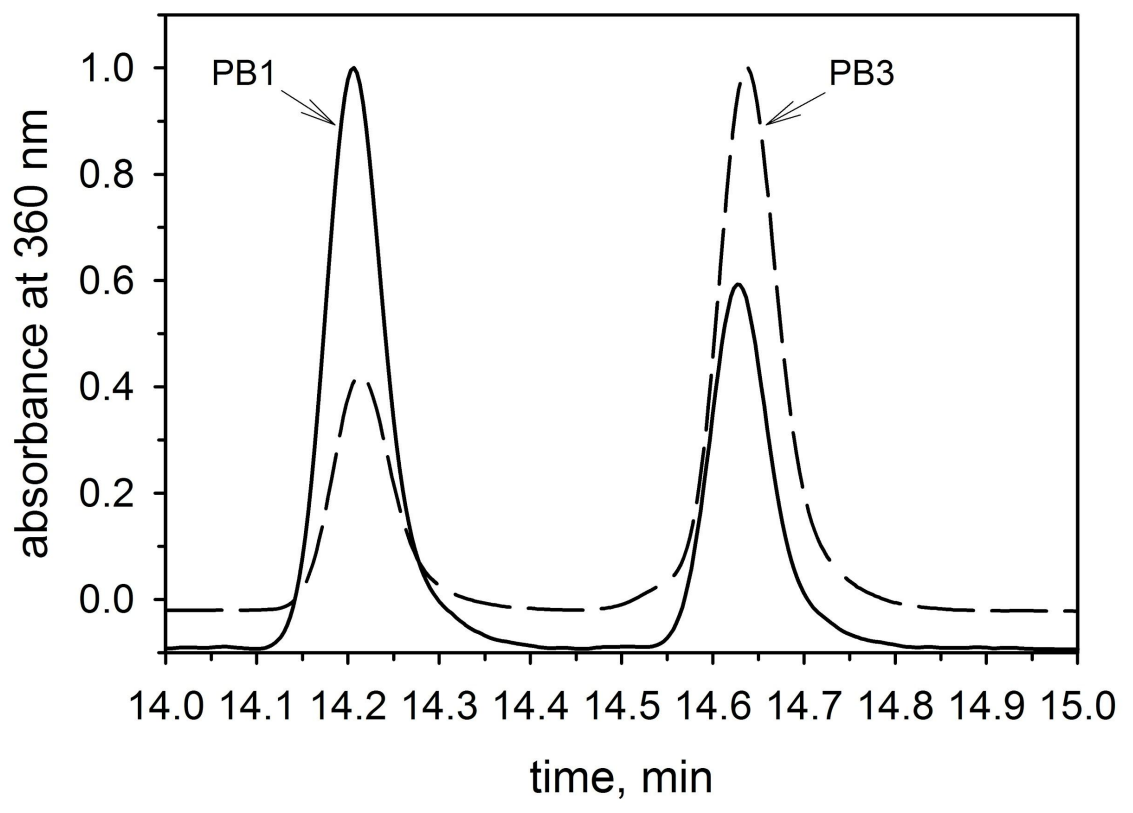

Figure S2. Chromatography of PB1 (solid line) and PB3 (dashed line) on C18 column. 


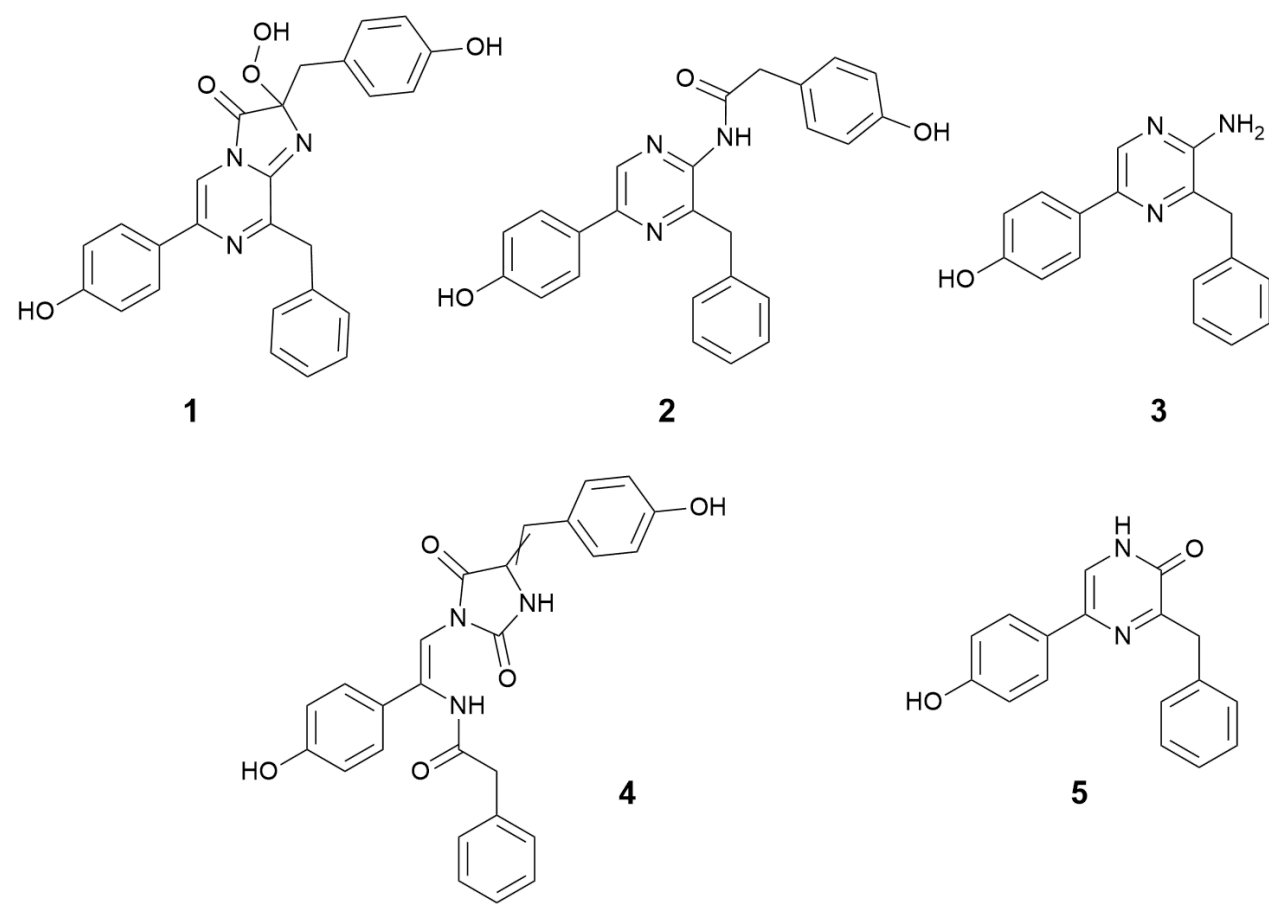

Figure S3. Chemical structures of 2-hydroperoxycoelenterazine 1 (chromophore of aequorin photoprotein) and the compounds, isolated from photoinactivated and active berovin, $\mathrm{Ca}^{2+}$-discharged berovin and active aequorin: $\quad$ coelenteramide $\quad 2, \quad$ coelenteramine $\quad 3$, $\mathrm{N}$-((Z)-2-(4-((Z,E)-4-hydroxybenzylidene)-2,5-dioxoimidazolidin-1-yl)-1-(4-hydroxyphenyl)vinyl)-2-phenylac etamide 4 and 3-benzyl-5-(4-hydroxyphenyl)pyrazin-2(1H)-one 5.

Table S1. Properties of the fractions, isolated from photoinactivated berovin (PB), active berovin (AB), $\mathrm{Ca}^{2+}$-discharged berovin (CDB) and active aequorin (AA).

\begin{tabular}{|c|c|c|c|c|c|}
\hline Fraction & $\begin{array}{l}\text { Retention time, } \\
\text { min }\end{array}$ & Absorption, nm & $\begin{array}{c}\text { Fluorescence, } \\
n \mathrm{~nm} \\
\left(\lambda_{\mathrm{ex}}=360 \mathrm{~nm}\right)\end{array}$ & $\begin{array}{l}{[\mathrm{M}+\mathrm{H}]+} \\
\text { (HRMS) }\end{array}$ & Major compounds \\
\hline \multicolumn{6}{|c|}{ Photoinactivated berovin (PB) } \\
\hline PB1 & 14.2 & 350 & $\mathrm{NF}^{[\mathrm{a}]}$ & 456.1554 & 4 \\
\hline PB2 & 14.5 & $270 / 360$ & 480 & 279.1132 & 4,5 \\
\hline PB3 & 14.6 & $280 / 350$ & NF & $\sim 456$ & 4 \\
\hline PB4 & 15.5 & $280 / 350$ & 440 & 278.1310 & 3 \\
\hline PB5 & 15.6 & $N D^{[b]}$ & ND & 412.1674 & 2 \\
\hline
\end{tabular}




\begin{tabular}{|c|c|c|c|c|c|}
\hline \multicolumn{6}{|c|}{ Active berovin (AB) } \\
\hline AB1 & 14.4 & $280 / 360$ & NF & 456.1563 & $N I^{[c]}$ \\
\hline AB2 & 14.5 & $270 / 360$ & 480 & 279.1142 & 5 \\
\hline AB3 & 15.5 & $280 / 350$ & 440 & 278.1288 & 3 \\
\hline AB4 & 15.6 & $280 / 350$ & 440 & 412.1656 & 2 \\
\hline \multicolumn{6}{|c|}{$\mathrm{Ca}^{2+}$-discharged berovin (CDB) } \\
\hline CDB1 & 14.5 & ND & ND & ND & $\mathrm{NI}$ \\
\hline CDB2 & 15.5 & $280 / 347$ & 440 & 278.412 & 3 \\
\hline CDB3 & 15.6 & $270 / 290 / 330$ & 440 & 412.16 & 2 \\
\hline \multicolumn{6}{|c|}{ Active aequorin (AA) } \\
\hline AA1 & 14.5 & ND & NF & ND & $\mathrm{NI}$ \\
\hline AA2 & 15.5 & $280 / 350$ & 440 & $\begin{array}{c}412 \& \\
278.1280\end{array}$ & 2,3 \\
\hline
\end{tabular}

NMR structural elucidation. PB1 fraction contained a mixture of two compounds in ratio $\sim 3: 1$, while PB3 contained only one of them. For the purposes of signal accumulation the fractions were combined for heteronuclear NMR experiments. ${ }^{1} \mathrm{H}-\mathrm{NMR}$ for one of the compounds revealed one phenyl, two phenol rings and two aromatic/double bond $\mathrm{CH}$-groups together with the benzylic $\mathrm{CH}_{2}$-group; $\mathrm{CH}$-groups were adjacent to the phenol rings, while $\mathrm{CH}_{2}$ was connected to the benzene moiety. The observed NMR chemical shifts and $2 \mathrm{D}$ correlation patterns of the second compound coincided with the carbon core of the first with the notable exception of the chemical environment for one $\mathrm{CH}$ group at the double bond. The signals at $6.54 / 6.43 \mathrm{ppm}$ in the $1 \mathrm{H}-\mathrm{NMR}$ spectrum, assigned to position 6 of the molecular skeleton, confirmed the presence of 2 geometric isomers. The most important feature of HMBC NMR for the compounds from PB1 and PB3 fractions was the absence of $\mathrm{C}-\mathrm{H}$ correlation between the protons in benzyl $\mathrm{CH}_{2}$ group and tertiary carbon in imidazole moiety, adjacent to the pyrazine 6-membered ring in 2-hydroperoxycoelenterazine 1, which, in contrast, could be found in all analogous structures.

NMR spectra (FID) of natural fractions and synthetic compound $\mathbf{4}$ are available free of charge at https://pubs.acs.org/. 


\section{Synthesis and purification of synthetic compounds}

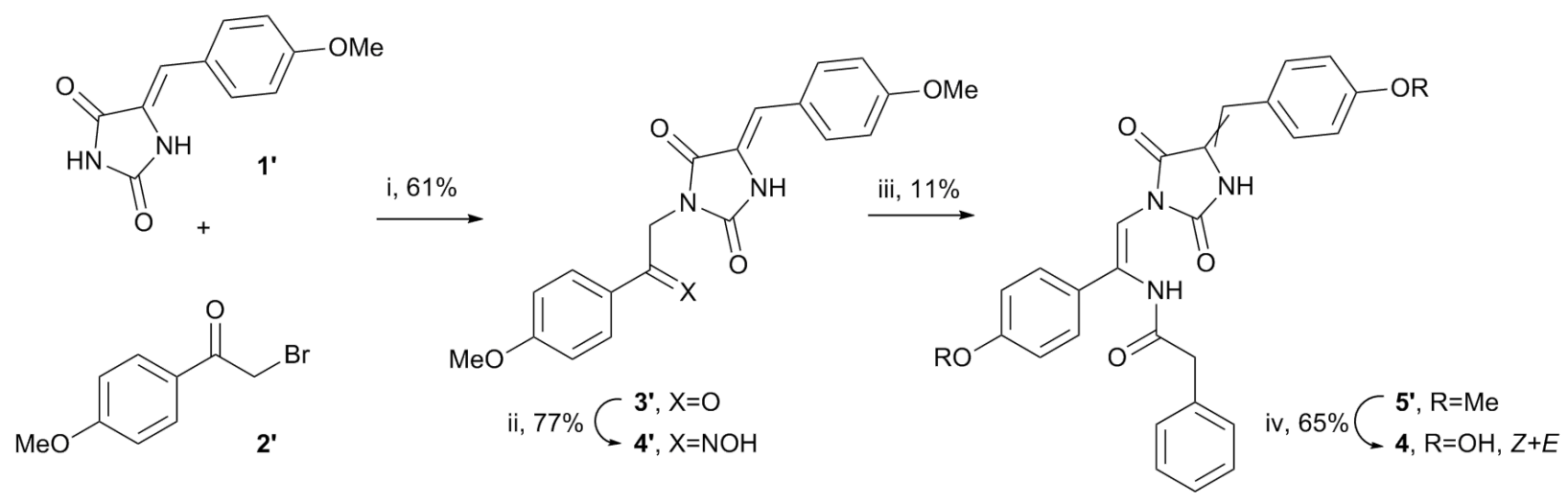

Figure S4. Synthesis of target compounds $4(Z+E)$ from starting hydantoin 1' and substituted bromoacetophenone 2'. Reagents and conditions: i. $\mathrm{K}_{2} \mathrm{CO}_{3}$, TBAB, DMF; ii. $\mathrm{NH}_{2} \mathrm{OH} \bullet \mathrm{HCl}, \mathrm{Py}: \mathrm{MeOH} 1: 1$; iii. $\mathrm{Fe}, \mathrm{PhAc}_{2} \mathrm{O}, \mathrm{TMSCl}, \mathrm{DMF} ;$ iv. $\mathrm{BBr}_{3}, \mathrm{CH}_{2} \mathrm{Cl}_{2}$.

Compounds 1' and 2' were obtained from commercially available 4-methoxyacetophenone, hydantoin and anisaldehyde according to described procedures ${ }^{5}$.

(Z)-5-(4-methoxybenzylidene)-3-(2-(4-methoxyphenyl)-2-oxoethyl)imidazolidine-2,4-dione (3'). To the solution of (4-methoxybenzylidene)hydantoin 1' $^{\prime}(1.09 \mathrm{~g}, 5 \mathrm{mmol})$ in dry DMF $(20 \mathrm{~mL})$ TBAB $(0.1 \mathrm{~g}, 0.3$ $\mathrm{mmol})$ and $\mathrm{K}_{2} \mathrm{CO}_{3}(0.69 \mathrm{~g}, 5 \mathrm{mmol})$ were added in Argon atmosphere. Reaction mixture was left stirring at $50^{\circ} \mathrm{C}$ for $30 \mathrm{~min}$, then a solution of 4-methoxyphenacyl bromide 2' (1.14 g, $5 \mathrm{mmol}$ ) in dry DMF (5 mL) was added. The reaction mixture was stirred at $50^{\circ} \mathrm{C}$ (oil bath) for 4 hours, the solvent was evaporated until approx. $2 \mathrm{~mL}$ left, and diluted with ethyl acetate $(20 \mathrm{~mL})$, resulting in a precipitate, which was filtered and dried in vacuo, yielding 3' as a white solid (1.23 g, 67\%). ${ }^{1} \mathrm{H}-\mathrm{NMR}$ (DMSO-d, $700 \mathrm{MHz}$ ): $\delta(\mathrm{ppm}) 8.03$ (d, $J=8.8 \mathrm{~Hz}, 2 \mathrm{H}), 7.77(\mathrm{~d}, J=8.8 \mathrm{~Hz}, 2 \mathrm{H}), 7.08(\mathrm{~d}, J=8.9 \mathrm{~Hz}, 2 \mathrm{H}), 6.92(\mathrm{~d}, J=8.8 \mathrm{~Hz}, 2 \mathrm{H}), 6.27(\mathrm{~s}, 1 \mathrm{H})$, $4.89(\mathrm{~s}, 1 \mathrm{H}), 3.87(\mathrm{~s}, 3 \mathrm{H}), 3.78(\mathrm{~s}, 3 \mathrm{H}) .{ }^{13} \mathrm{C}-\mathrm{NMR}$ (DMSO-d $\left.6,75 \mathrm{MHz}\right) \delta(\mathrm{ppm}): 191.1,163.7,158.7,157.7$, 130.9, 130.4, 127.3, 127.2, 114.2, 114.0, 107.6, 55.7, 55.2, 44.5. HRMS (ESI) m/z: calcd for $\mathrm{C}_{20} \mathrm{H}_{19} \mathrm{~N}_{2} \mathrm{O}_{5}{ }^{+}$ $([\mathrm{M}+\mathrm{H}]+)$ 367.1288, found 367.1312 .

5-((Z)-4-hydroxybenzylidene)-3-((Z,E)-2-(4-hydroxyphenyl)-2-(methylimino)ethyl)imidazolidine-2,4-di one (4'). To the solution of 3' (403 mg, $1.1 \mathrm{mmol})$ in $\mathrm{Py}: \mathrm{MeOH} 1: 1(30 \mathrm{~mL}) \mathrm{NH}_{2} \mathrm{OH}^{*} \mathrm{HCl}(681 \mathrm{mg}, 9,8$ $\mathrm{mmol}$ ) was added. The reaction mixture was refluxed (oil bath) for 72 hours, then the solvent was evaporated under reduced pressure. Cold water $(10 \mathrm{~mL})$ was added to the residue, the precipitate was filtered and dried in vacuo yielding 4' as a mixture of Z/E oximes, a white solid (323 mg, 77\%).

4'a: ${ }^{1} \mathrm{H}-\mathrm{NMR}$ (DMSO-d $6,700 \mathrm{MHz}$ ): $\delta$ (ppm) 11,05 (s, 1H), 10.67 (br. s, 1H), 7.61 (d, J = 8.9 Hz, 2H), 7.58 $(\mathrm{d}, J=8.8 \mathrm{~Hz}, 2 \mathrm{H}), 6.96(\mathrm{~d}, J=8.6 \mathrm{~Hz}, 2 \mathrm{H}), 6.93(\mathrm{~d}, J=8.6 \mathrm{~Hz}, 2 \mathrm{H}), 6.51(\mathrm{~s}, 1 \mathrm{H}), 4.53(\mathrm{~s}, 2 \mathrm{H}), 3.80(\mathrm{~s}$, $3 \mathrm{H}), 3.78(\mathrm{~s}, 3 \mathrm{H})$.

4'b: ${ }^{1} \mathrm{H}-\mathrm{NMR}\left(\mathrm{DMSO}-\mathrm{d}_{6}, 700 \mathrm{MHz}\right.$ ): $\delta$ (ppm) 11,39 (s, 1H), 10.58 (br. s, 1H), 7.56 (d, J = 8.8 Hz, 2H), 7.39 $(\mathrm{d}, J=8.9 \mathrm{~Hz}, 2 \mathrm{H}), 6.94(\mathrm{~d}, J=8.6 \mathrm{~Hz}, 2 \mathrm{H}), 6.88(\mathrm{~d}, J=8.9 \mathrm{~Hz}, 2 \mathrm{H}), 6.43(\mathrm{~s}, 1 \mathrm{H}), 4.72(\mathrm{~s}, 2 \mathrm{H}), 3.80(\mathrm{~s}$, $3 \mathrm{H}), 3.78(\mathrm{~s}, 3 \mathrm{H})$.

5 (a) C. Lia, C. Tang, Z. Hub, C. Zhao, C. Li, S. Zhang, C. Dong, H.-B. Zhou, J. Huang. Bioorg. Med. Chem. 2016, 24, 3062-3074. (b) D. J. Burkett, B. N. Wyatt, M. Mews, A. Bautista, R. Engel, C. Dockendorff, W. A. Donaldson, M. St. Maurice, Bioorg. Med. Chem. 2019, 27, 4041-4047. 
4': ${ }^{13} \mathrm{C}-\mathrm{NMR}$ (DMSO-d 6 , $75 \mathrm{MHz}$ ): $\delta$ (ppm) 163.9, 163.7, 159.7, 159.5, 154.7, 154.5, 152.1, 147.6, 131.3, 129.8, 127.9, 126.8, 125.2, 125.1, 124.6, 124.3, 123.5, 114.3, 113.6, 113.4, 110.2, 110.1, 55.3, 55.1, 33.8. HRMS (ESI) m/z: calcd for $\mathrm{C}_{20} \mathrm{H}_{20} \mathrm{~N}_{3} \mathrm{O}_{5}{ }^{+}\left([\mathrm{M}+\mathrm{H}]^{+}\right)$382.1397, found 382.1417.

N-((Z,E)-2-(4-((Z)-4-methoxybenzylidene)-2,5-dioxoimidazolidin-1-yl)-1-(4-methoxyphenyl)vinyl)-2-ph enylacetamide (5'). To a solution of 4' $(100 \mathrm{mg}, 0.26 \mathrm{mmol})$ in dry DMF (1.5 mL), Fe powder (112 mg, 2 $\mathrm{mmol})$, then a solution of freshly obtained phenylacetic anhydride ${ }^{6}(508 \mathrm{mg}, 2 \mathrm{mmol})$ in dry DMF $(1.5 \mathrm{~mL})$ and $\mathrm{TMSCl}\left(10 \mathrm{mcL}\right.$ ) were added in argon atmosphere. Reaction mixture was stirred at $50^{\circ} \mathrm{C}$ (oil bath) for 10 hours, and then diluted with ice-cold saturated $\mathrm{NaHCO}_{3}$ aqueous solution $(10 \mathrm{~mL})$, washed with $\mathrm{Et}_{2} \mathrm{O}(3$ x $10 \mathrm{~mL}$ ), dried with $\mathrm{Na}_{2} \mathrm{SO}_{4}$ and then concentrated in vacuo. Crude product was further purified by RP-LC using Puriflash 5.250 system (Interchim, France) (PF30C18HP-F0012 flash column (Interchim, France): $0.1 \%$ aqueous $\mathrm{HCOOH} /$ acetonitrile, linear gradient $-50-100 \%$ acetonitrile, flow rate $=15 \mathrm{~mL} / \mathrm{min}, \lambda=260$ \& $360 \mathrm{~nm}$ ). Purification yielded 5' as a light-yellow solid, a mixture of Z/E isomers (14 mg, 11\%). Z-isomer was separated from $E$-isomer in the next step.

5'Z: ${ }^{1} \mathrm{H}-\mathrm{NMR}\left(\mathrm{CDCl}_{3}, 700 \mathrm{MHz}\right): \delta(\mathrm{ppm}) 8.71(\mathrm{~s}, 1 \mathrm{H}), 8.39(\mathrm{~s}, 1 \mathrm{H}), 7.47(\mathrm{~d}, \mathrm{~J}=8.4 \mathrm{~Hz}, 2 \mathrm{H}), 7.49-7.45$ (m, $4 \mathrm{H}), 7.31-7.39(\mathrm{~m}, 3 \mathrm{H}), 6.94(\mathrm{~d}, J=8.3 \mathrm{~Hz}, 2 \mathrm{H}), 6.85(\mathrm{~d}, J=8.4 \mathrm{~Hz}, 2 \mathrm{H}), 6.78(\mathrm{~s}, 1 \mathrm{H}), 6.28(\mathrm{~s}, 1 \mathrm{H}), 3.88$ (s, 3H), $3.86(\mathrm{~s}, 3 \mathrm{H}), 3.75$ (s, 2H). ${ }^{13} \mathrm{C}-\mathrm{NMR}\left(\mathrm{CDCl}_{3}, 176 \mathrm{MHz}\right): \delta$ (ppm) 170.4, 162.4, 160.5, 160.2, 153.2, 134.4, 133.4, 131.1, 129.7, 129.0, 127.7, 127.4, 127.1, 125.2, 114.8, 114.0, 113.6, 107.5, 55.4, 55.3, 44.4.

5'E: ${ }^{1} \mathrm{H}-\mathrm{NMR}\left(\mathrm{CDCl}_{3}, 700 \mathrm{MHz}\right): \delta(\mathrm{ppm}) 8.00(\mathrm{~s}, 1 \mathrm{H}), 7.49-7.45(\mathrm{~m}, 2 \mathrm{H}), 7.31-7.39(\mathrm{~m}, 5 \mathrm{H}), 7.25(\mathrm{~s}, 1 \mathrm{H})$, $7.16(\mathrm{~d}, J=8.3 \mathrm{~Hz}, 2 \mathrm{H}), 6.96(\mathrm{~d}, J=8.7 \mathrm{~Hz}, 2 \mathrm{H}), 6.83(\mathrm{~d}, J=8.6 \mathrm{~Hz}, 2 \mathrm{H}), 6.76(\mathrm{~s}, 1 \mathrm{H}), 6.64(\mathrm{~s}, 1 \mathrm{H}), 3.86$ (s, 3H), $3.79(\mathrm{~s}, 3 \mathrm{H}), 3.78(\mathrm{~s}, 2 \mathrm{H}) .{ }^{13} \mathrm{C}-\mathrm{NMR}\left(\mathrm{CDCl}_{3}, 176 \mathrm{MHz}\right): \delta(\mathrm{ppm})$ 169.4, 162.9, 160.2, 160.1, 139.4, 133.9, 130.5, 129.5, 129.4, 128.8, 128.7, 126.8, 125.5, 114.9, 114.3, 111.9, 104.4, 55.3, 55.2, 44.9.

HRMS (ESI) m/z: calcd for $\mathrm{C}_{28} \mathrm{H}_{26} \mathrm{~N}_{3} \mathrm{O}_{5}\left([\mathrm{M}+\mathrm{H}]^{+}\right)$484.1867, found 484.1889.

N-((Z)-2-(4-((Z,E)-4-hydroxybenzylidene)-2,5-dioxoimidazolidin-1-yl)-1-(4-hydroxyphenyl)vinyl)-2-ph enylacetamide (4). To the solution of 5' $\left(7 \mathrm{mg}, 0.014 \mathrm{mmol}\right.$ ) in dry $\mathrm{CH}_{2} \mathrm{Cl}_{2}(0.25 \mathrm{~mL}) 0.3 \mathrm{M} \mathrm{BBr}_{3}$ in dry $\mathrm{CH}_{2} \mathrm{Cl}_{2}(0.25 \mathrm{~mL})$ was added dropwise at $0^{\circ} \mathrm{C}$ in Argon atmosphere. The reaction mixture was stirred at r.t. for 2 hours, then diluted with ice-cold phosphate buffer $(\mathrm{pH} 7,3 \mathrm{~mL})$ at $0^{\circ} \mathrm{C}$, and extracted with ethyl acetate $(3 \times 3 \mathrm{~mL})$. Organic phase was dried with $\mathrm{Na}_{2} \mathrm{SO}_{4}$ and concentrated. Crude product was further purified by HPLC using WAVE® 4500 HPLC System (Transgenomic, USA) (Alltech® Apollo ${ }^{\text {TM }}$ C18 column $(150 \times 4.6 \mathrm{~mm}, 5 \mu \mathrm{m}$; Grace, USA): $0.1 \%$ aqueous $\mathrm{HCOOH} /$ acetonitrile, linear gradient $-30-100 \%$ acetonitrile, flow rate $=1 \mathrm{~mL} / \mathrm{min}, \lambda=260 \mathrm{~nm}$ ). tR = $8.6 \mathrm{~min}$ (major), $9.2 \mathrm{~min}$ (minor). Purification yielded a mixture of $4(Z+E)$ as a yellow solid $(4.5 \mathrm{mg}, 65 \%)$. 1D and 2D NMR were recorded from different fractions of 4 therefore represent a various $Z / E$ ratio.

4Z: ${ }^{1} \mathrm{H}-\mathrm{NMR}\left(\mathrm{CD}_{3} \mathrm{OD}, 600 \mathrm{MHz}\right): \delta(\mathrm{ppm}) 7.93(\mathrm{~d}, J=8.7 \mathrm{~Hz}, 2 \mathrm{H}), 7.33(\mathrm{~d}, J=8.4 \mathrm{~Hz}, 2 \mathrm{H}), 7.27(\mathrm{~d}, J=7.1$ $\mathrm{Hz}, 2 \mathrm{H}), 7.16-7.20(\mathrm{~m}, 3 \mathrm{H}), 6.79-6.82(\mathrm{~m}, 4 \mathrm{H}), 6.43(\mathrm{~s}, 1 \mathrm{H}), 6.21(\mathrm{~s}, 1 \mathrm{H}), 3.64(\mathrm{~s}, 2 \mathrm{H}) .{ }^{13} \mathrm{C}-\mathrm{NMR}$ (DMSO- $d_{6}, 150 \mathrm{MHz}$ ): $\delta$ (ppm) 170.1, 159.4, 158.5, 158.4, 152.7, 135.1, 133.0, 132.3, 128.9, 128.2, 127.7, 126.6, 126.5, 124.7, 120.0, 114.8, 106.6, 42.7.

4E: ${ }^{1} \mathrm{H}-\mathrm{NMR}\left(\mathrm{CD}_{3} \mathrm{OD}, 800 \mathrm{MHz}\right): \delta(\mathrm{ppm}) 7.44(\mathrm{~d}, J=8.4 \mathrm{~Hz}, 2 \mathrm{H}), 7.33(\mathrm{~d}, J=8.2 \mathrm{~Hz}, 4 \mathrm{H}), 7.26-7.28(\mathrm{~m}$, $2 \mathrm{H}), 7.19-7.21(\mathrm{~m}, 1 \mathrm{H}), 6.89(\mathrm{~d}, J=8.4 \mathrm{~Hz}, 2 \mathrm{H}), 6.80(\mathrm{~d}, J=8.4 \mathrm{~Hz}, 2 \mathrm{H}), 6.54(\mathrm{~s}, 1 \mathrm{H}), 6.22(\mathrm{~s}, 1 \mathrm{H}), 3.64$ (s, 2H). ${ }^{13} \mathrm{C}-\mathrm{NMR}$ (DMSO-d $\left.\mathrm{D}_{6} 201 \mathrm{MHz}\right): \delta$ (ppm) 170.1, 162.0, 158.4, 153.8, 135.3, 133.1, 130.9, 128.9, 128.1, 127.7, 126.6, 126.5, 124.2, 115.5, 114.8, 112.4, 106.4, 42.8.

HRMS (ESI) m/z: calcd for $\mathrm{C}_{26} \mathrm{H}_{22} \mathrm{~N}_{3} \mathrm{O}_{5}{ }^{+}[\mathrm{M}+\mathrm{H}]+456.1554$, found 456.1569.

\footnotetext{
${ }^{6}$ S. Beasley, K. Nguyen, M. Fazio, R. C. Spitale, Tetrahedron Lett., 2018, 59, 3912-3915.
} 

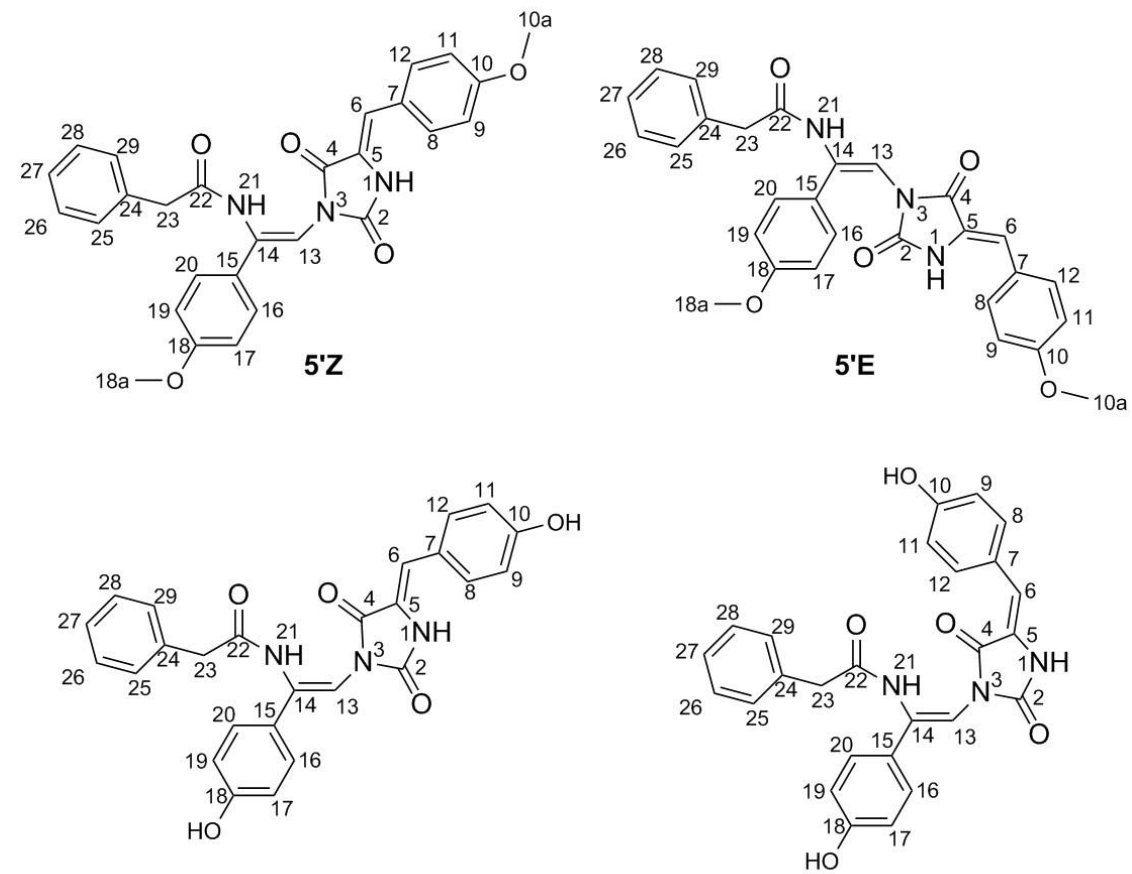

$4 Z$

4E

Figure S5. Structures of compounds $5^{\prime} Z, 5^{\prime} E, 4 Z$ and $4 E$ with atom numbering, that corresponds to the chemical shifts given in Table $\mathbf{S 2}$.

Table S2. Chemical shifts of compounds in 5' $^{\mathrm{CDCl}_{3}}$ (Bruker Avance $700 \mathrm{MHz}$ ) and 4 in $\mathrm{CD}_{3} \mathrm{OD}$ (Bruker Avance $600 \mathrm{MHz}$ ). Atom numbering according to Fig. S5.

\begin{tabular}{|c|c|c|c|c|c|c|c|c|}
\hline \multirow{2}{*}{$\begin{array}{l}\text { Atom } \\
\text { number }\end{array}$} & \multicolumn{2}{|c|}{$5^{\prime}(Z, Z)$} & \multicolumn{2}{|c|}{$5^{\prime}(E, Z)$} & \multicolumn{2}{|c|}{$4(Z, E)$} & \multicolumn{2}{|c|}{$4(Z, Z)$} \\
\hline & $\begin{array}{c}\delta^{1} \mathrm{H} \\
(\mathrm{ppm}), \\
\mathrm{CDCl}_{3}\end{array}$ & $\begin{array}{c}\delta{ }^{13} \mathrm{C}(\mathrm{ppm}) / \\
\delta{ }^{15} \mathrm{~N}(\mathrm{ppm}) \\
\mathrm{CDCl}_{3}\end{array}$ & $\begin{array}{c}\delta{ }^{1} \mathrm{H} \\
(\mathrm{ppm}), \\
\mathrm{CDCl}_{3}\end{array}$ & $\begin{array}{c}\delta^{13} \mathrm{C}(\mathrm{ppm}) / \\
\delta{ }^{15} \mathrm{~N}(\mathrm{ppm}) \\
\mathrm{CDCl}_{3}\end{array}$ & $\begin{array}{c}\delta^{1} \mathrm{H} \\
(\mathrm{ppm}) \\
\mathrm{CD}_{3} \mathrm{OD}\end{array}$ & $\begin{array}{c}\delta^{13} \mathrm{C} \\
(\mathrm{ppm}) \\
\mathrm{CD}_{3} \mathrm{OD}\end{array}$ & $\begin{array}{c}\delta{ }^{1} \mathrm{H} \\
(\mathrm{ppm}) \\
\mathrm{CD}_{3} \mathrm{OD}\end{array}$ & $\begin{array}{c}\delta^{13} \mathrm{C} \\
(\mathrm{ppm}), \\
\mathrm{CD}_{3} \mathrm{OD}\end{array}$ \\
\hline $1(\mathrm{~N})$ & 8.82 & 106.4 & 8.09 & 105.2 & $x$ & $x$ & $x$ & $x$ \\
\hline 2 & $x$ & 153.2 & $x$ & $\mathrm{n} / \mathrm{a}$ & $x$ & 153.8 & $x$ & 152.7 \\
\hline $3(\mathrm{~N})$ & $x$ & $x$ & $x$ & $x$ & $x$ & $x$ & $x$ & $x$ \\
\hline 4 & $x$ & 162.4 & $x$ & 162.9 & $x$ & 162.0 & $x$ & 159.4 \\
\hline 5 & $x$ & $\mathrm{n} / \mathrm{a}$ & $x$ & $\mathrm{n} / \mathrm{a}$ & $x$ & $\mathrm{n} / \mathrm{a}$ & $x$ & $\mathrm{n} / \mathrm{a}$ \\
\hline 6 & 6.78 & 113.6 & 6.64 & 111.9 & 6.54 & 112.4 & 6.43 & 120.0 \\
\hline 7 & $x$ & 125.2 & $x$ & 125.5 & $x$ & 124.2 & $x$ & 124.7 \\
\hline 8 & 7.47 & 131.1 & 7.35 & 130.5 & 7.44 & 130.9 & 7.93 & 132.3 \\
\hline 9 & 6.94 & 114.8 & 6.96 & 114.9 & 6.89 & 115.5 & 6.81 & 114.8 \\
\hline
\end{tabular}




\begin{tabular}{|l|c|c|c|c|c|c|c|c|}
\hline 10 & $\mathrm{x}$ & 160.5 & $\mathrm{x}$ & 160.2 & $\mathrm{x}$ & 158.4 & $\mathrm{x}$ & 158.4 \\
\hline $10 \mathrm{a}$ & 3.88 & 55.3 & 3.86 & 55.3 & $\mathrm{x}$ & $\mathrm{x}$ & $\mathrm{x}$ & $\mathrm{x}$ \\
\hline 13 & 6.28 & 107.5 & 7.25 & 104.4 & 6.22 & 106.4 & 6.21 & 106.6 \\
\hline 14 & $\mathrm{x}$ & 133.4 & $\mathrm{x}$ & 139.4 & $\mathrm{x}$ & 133.1 & $\mathrm{x}$ & 133.0 \\
\hline 15 & $\mathrm{x}$ & 127.1 & $\mathrm{x}$ & 126.8 & $\mathrm{x}$ & 126.6 & $\mathrm{x}$ & 126.6 \\
\hline 16 & 7.35 & 127.7 & 7.16 & 128.7 & 7.33 & 127.7 & 7.33 & 127.7 \\
\hline 17 & 6.85 & 114.0 & 6.83 & 114.3 & 6.80 & 114.8 & 6.80 & 114.8 \\
\hline 18 & $\mathrm{x}$ & 160.2 & $\mathrm{x}$ & 160.1 & $\mathrm{x}$ & 158.4 & $\mathrm{x}$ & 158.5 \\
\hline $18 \mathrm{a}$ & 3.86 & 55.3 & 3.79 & 55.2 & $\mathrm{x}$ & $\mathrm{x}$ & $\mathrm{x}$ & $\mathrm{x}$ \\
\hline $21(\mathrm{~N})$ & 8.39 & 130.3 & 6.76 & 133.1 & $\mathrm{x}$ & $\mathrm{x}$ & $\mathrm{x}$ & $\mathrm{x}$ \\
\hline 22 & $\mathrm{x}$ & 170.4 & $\mathrm{x}$ & 169.4 & $\mathrm{x}$ & 170.1 & $\mathrm{x}$ & 170.1 \\
\hline 23 & 3.75 & 44.4 & 3.78 & 44.9 & 3.64 & 42.8 & 3.64 & 42.7 \\
\hline 24 & $\mathrm{x}$ & 134.4 & $\mathrm{x}$ & 133.9 & $\mathrm{x}$ & 135.3 & $\mathrm{x}$ & 135.1 \\
\hline 25 & 7.43 & 129.7 & 7.36 & 129.5 & 7.33 & 128.9 & 7.27 & 128.9 \\
\hline 26 & 7.42 & 129.0 & 7.43 & 129.4 & 7.27 & 128.1 & 7.19 & 128.2 \\
\hline 27 & 7.34 & 127.4 & 7.38 & 128.8 & 7.19 & 126.5 & 7.17 & 126.5 \\
\hline
\end{tabular}




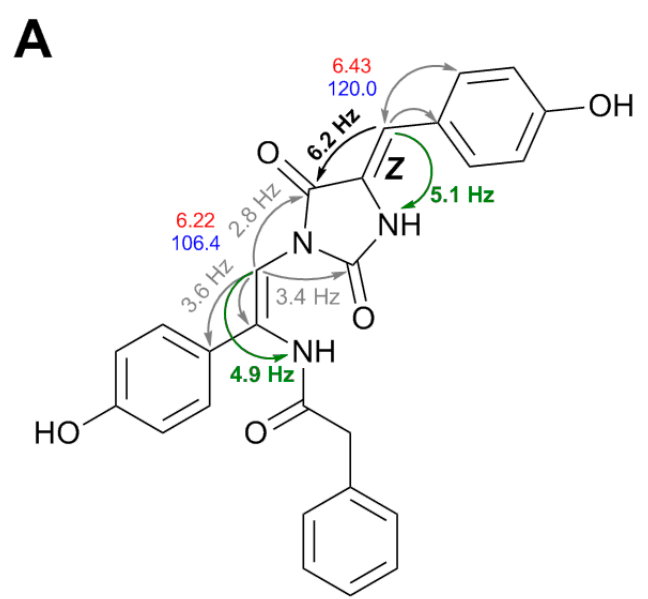

$4(Z)$

B

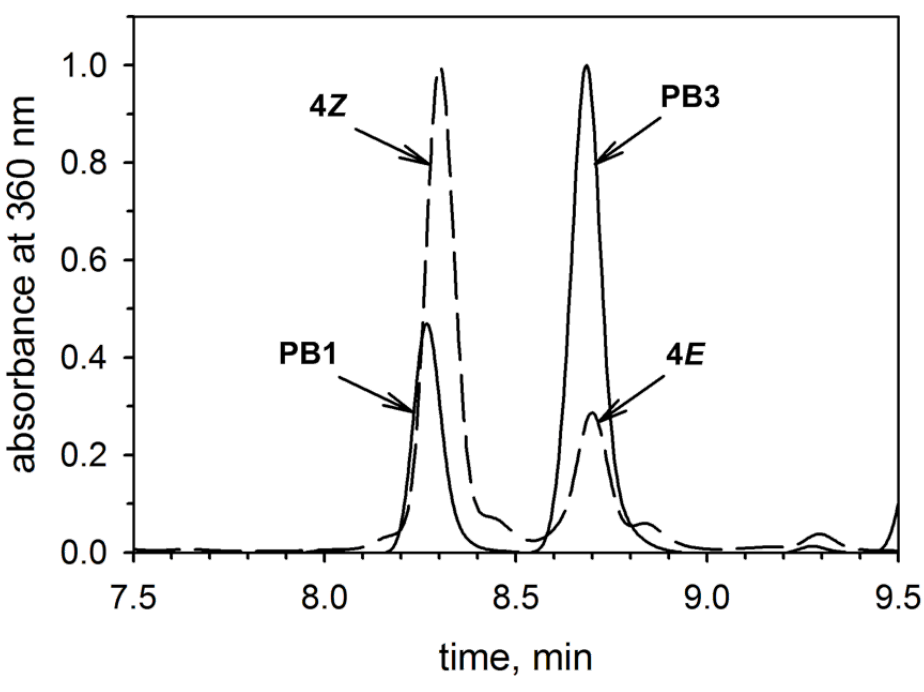

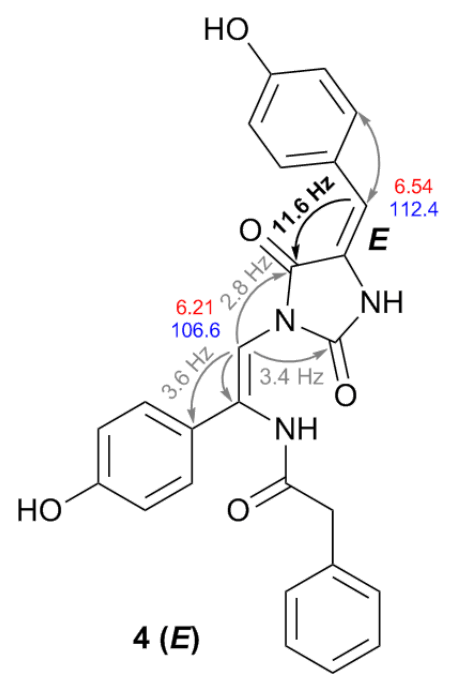

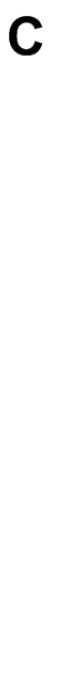

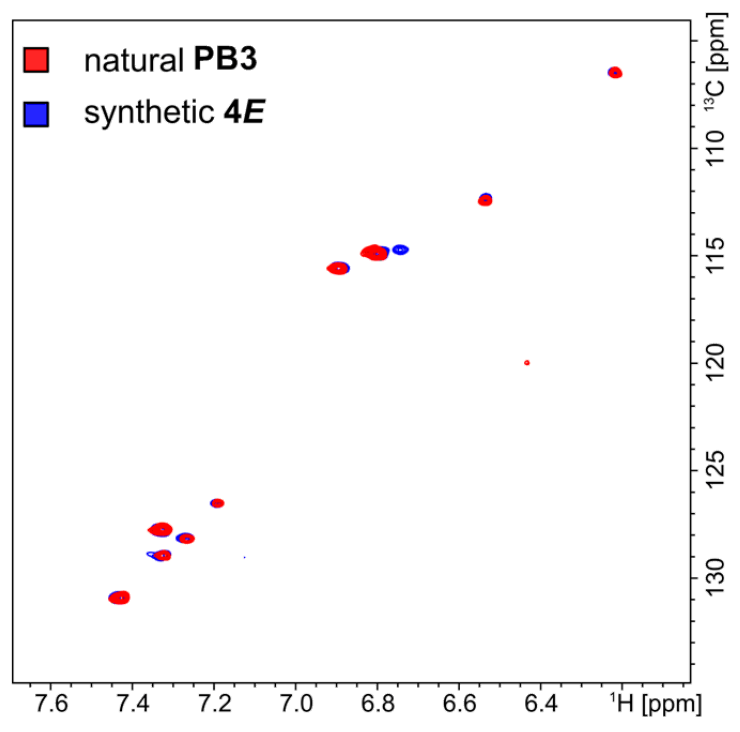

Figure S6. Structures of synthetic compounds $4 \mathrm{Z} / \mathrm{E}$, identical to the photoinactivation products from fractions PB1 and PB3. A. Structures of $4 Z$ and $4 E$ with chemical shifts of hydrogen (red) and carbon (blue) in key positions, key HMBC correlations (indicated by arrows: ${ }^{1} \mathrm{H}-{ }^{13} \mathrm{C}$ grey and black, ${ }^{1} \mathrm{H}-{ }^{15} \mathrm{~N}$ green) and major $\mathrm{J}$-coupling constants, confirming the configuration, in $\mathrm{CD}_{3} \mathrm{OD}$. B. Comparisons of HPLC profiles of natural and synthetic fractions of PB1/3 - compounds 4 Z/E. C. Overlay of ${ }^{1} \mathrm{H}-{ }^{13} \mathrm{C}$ HSQC NMR spectra recorded for $4 E$ from synthetic sample (blue) and natural sample of PB1/3 (red) 
${ }^{1} \mathrm{H}$ and ${ }^{13} \mathrm{C}$ NMR of the synthesized compounds

${ }^{1} \mathrm{H}-\mathrm{NMR}\left(\mathrm{DMSO}-d_{6}, 700 \mathrm{MHz}\right)$
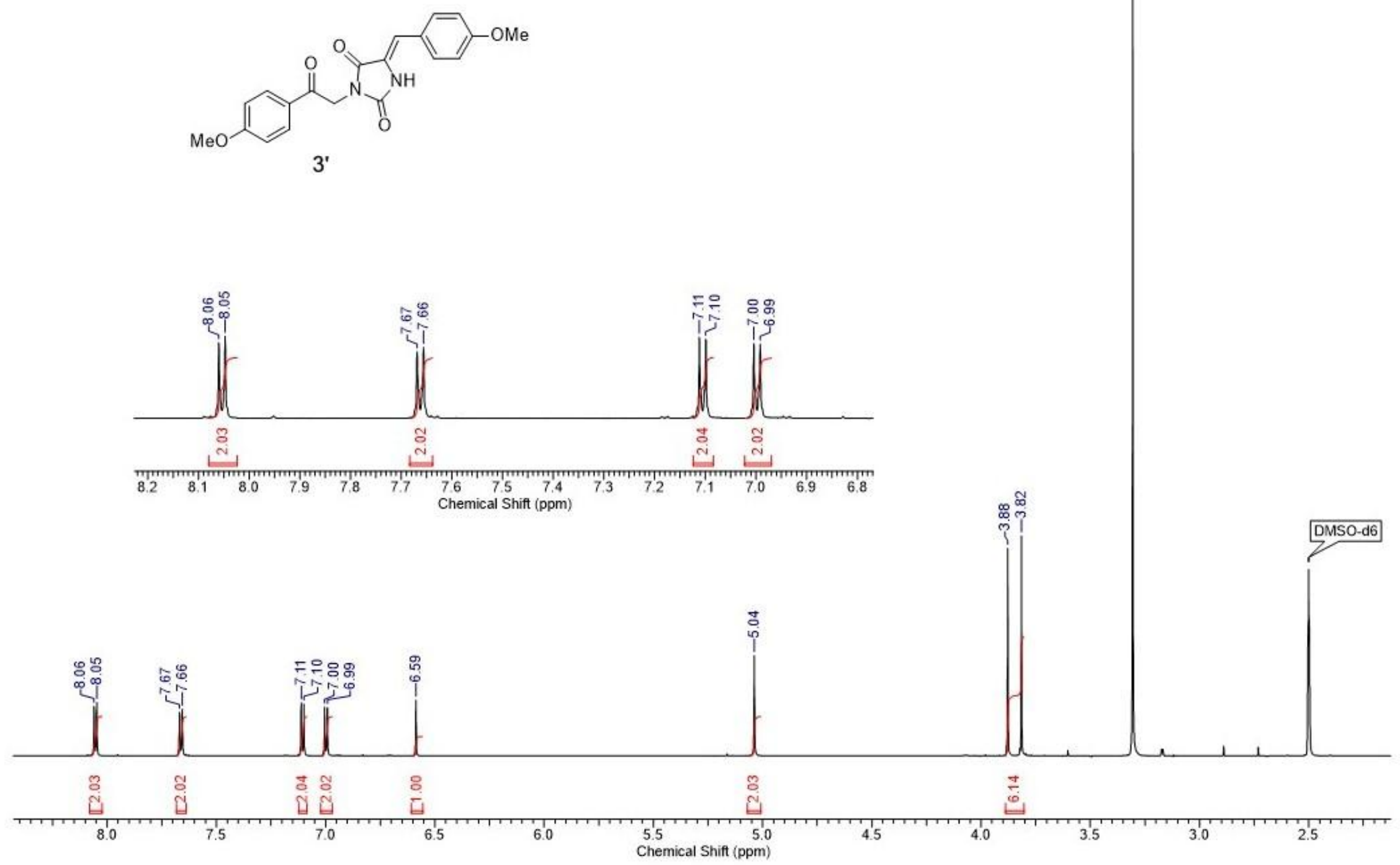

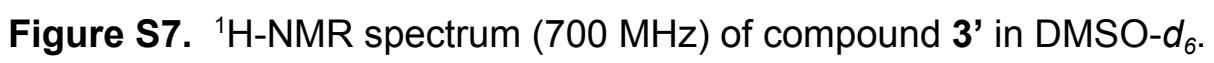


${ }^{13} \mathrm{C}-\mathrm{NMR}$ (DMSO- $\left.d_{6}, 75 \mathrm{MHz}\right)$
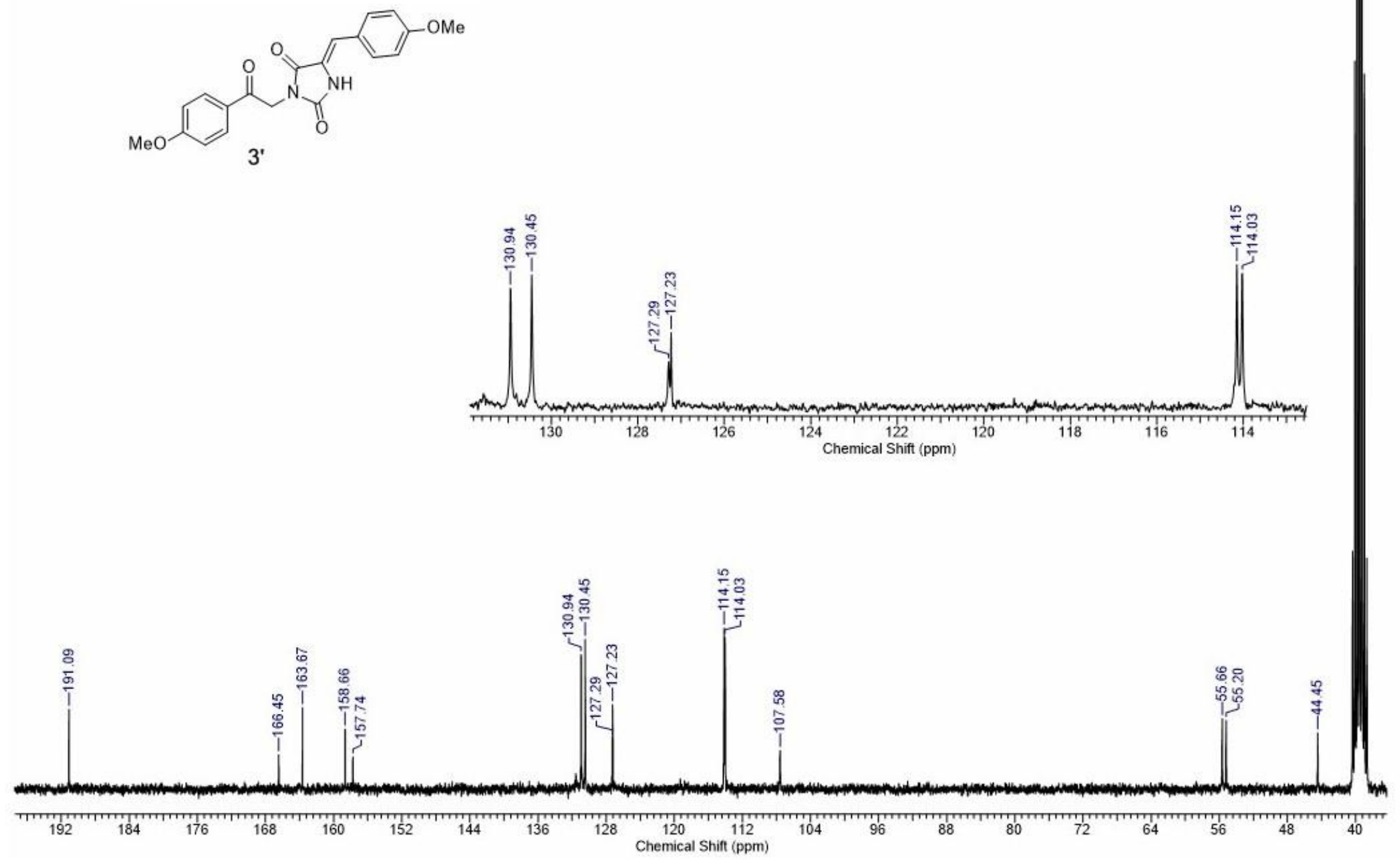

Figure S8. ${ }^{13} \mathrm{C}-\mathrm{NMR}$ spectrum $(75 \mathrm{MHz})$ of compound $\mathbf{3}^{\prime}$ in DMSO- $d_{6}$. 
${ }^{1} \mathrm{H}-\mathrm{NMR}\left(\mathrm{DMSO}-\mathrm{d}_{6}, 700 \mathrm{MHz}\right)$<smiles>COC1=CC=C(/C=C2\NC(=O)N(CC(N=O)c3ccc(OC)cc3)C2=O)CC1</smiles>
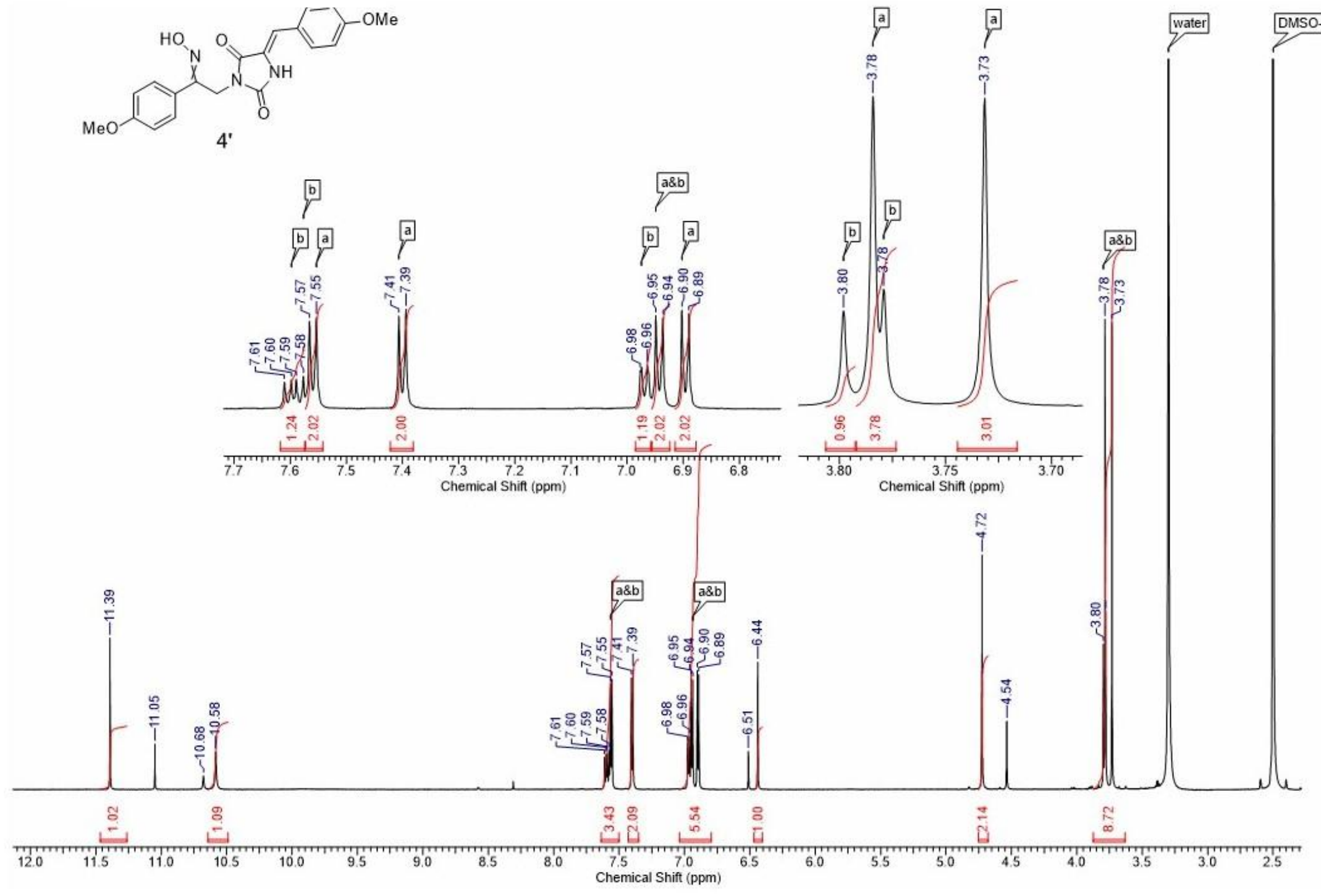

Figure S9. ${ }^{1} \mathrm{H}-\mathrm{NMR}$ spectrum $(700 \mathrm{MHz})$ of compound 4' in DMSO- $d_{6}$ (two geometric isomers of oxime 4'a и 4'b). 
${ }^{13} \mathrm{C}-\mathrm{NMR}$ (DMSO- $d_{6}, 75 \mathrm{MHz}$ )
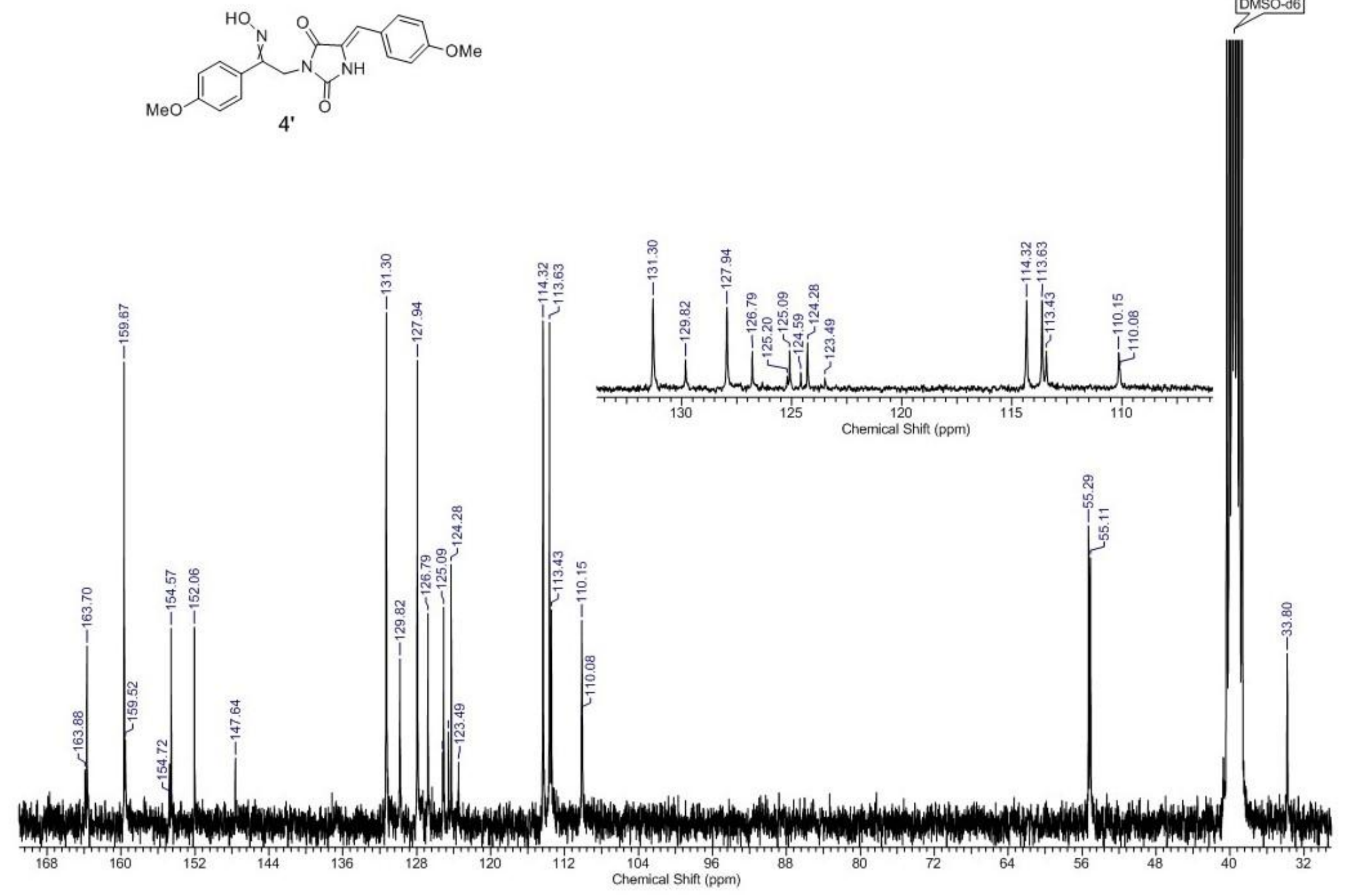

Figure S10. ${ }^{13} \mathrm{C}-\mathrm{NMR}$ spectrum (75 MHz) of compound 4' in DMSO- $d_{6}$ (two geometric isomers of oxime 4'a и 4'b). 


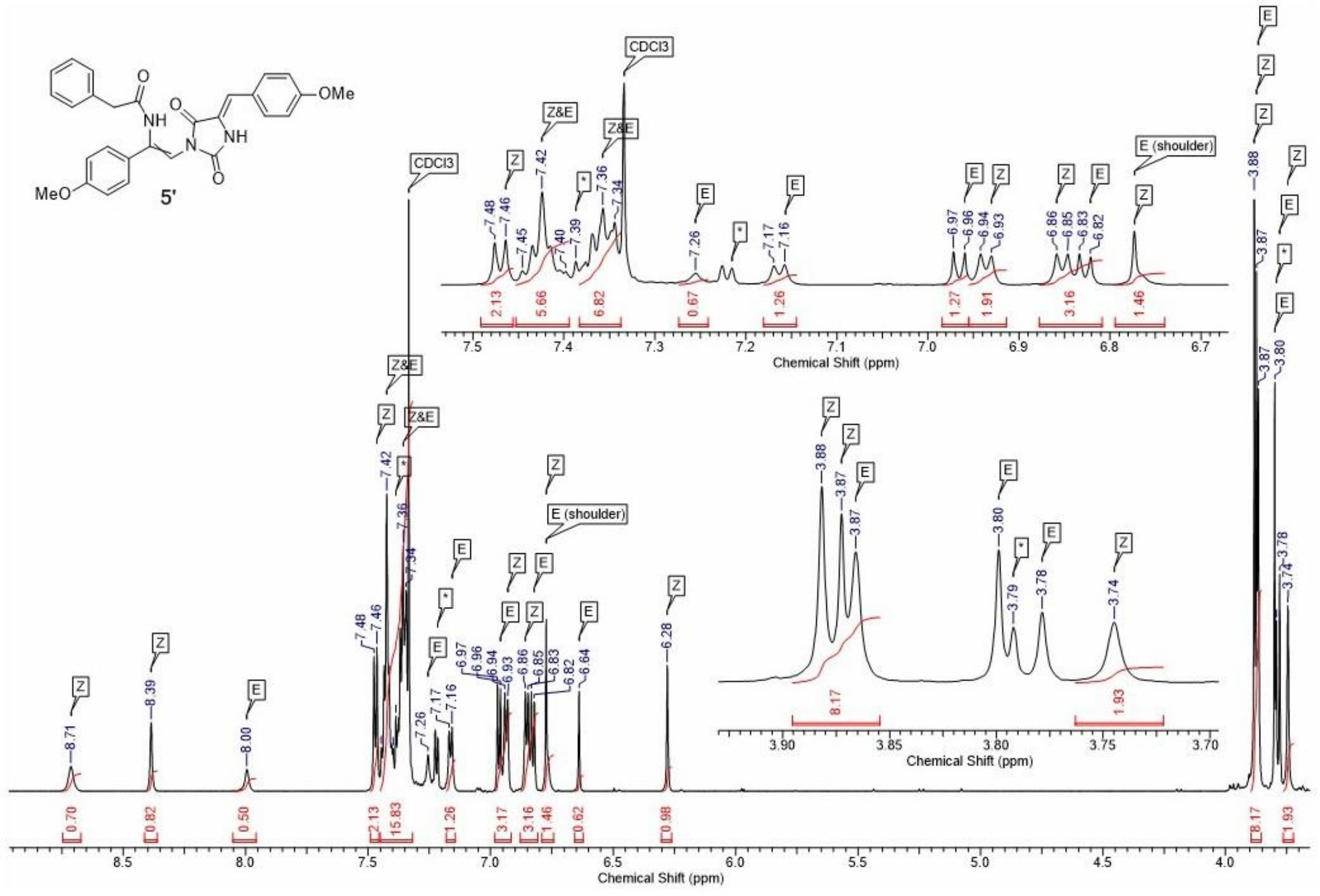

Figure S11. ${ }^{1} \mathrm{H}-\mathrm{NMR}$ spectrum $(700 \mathrm{MHz})$ of $\mathbf{5}^{\prime}(Z+E)$ in $\mathrm{CDCl}_{3}\left({ }^{*}\right.$ - dibenzyl ketone impurity). 


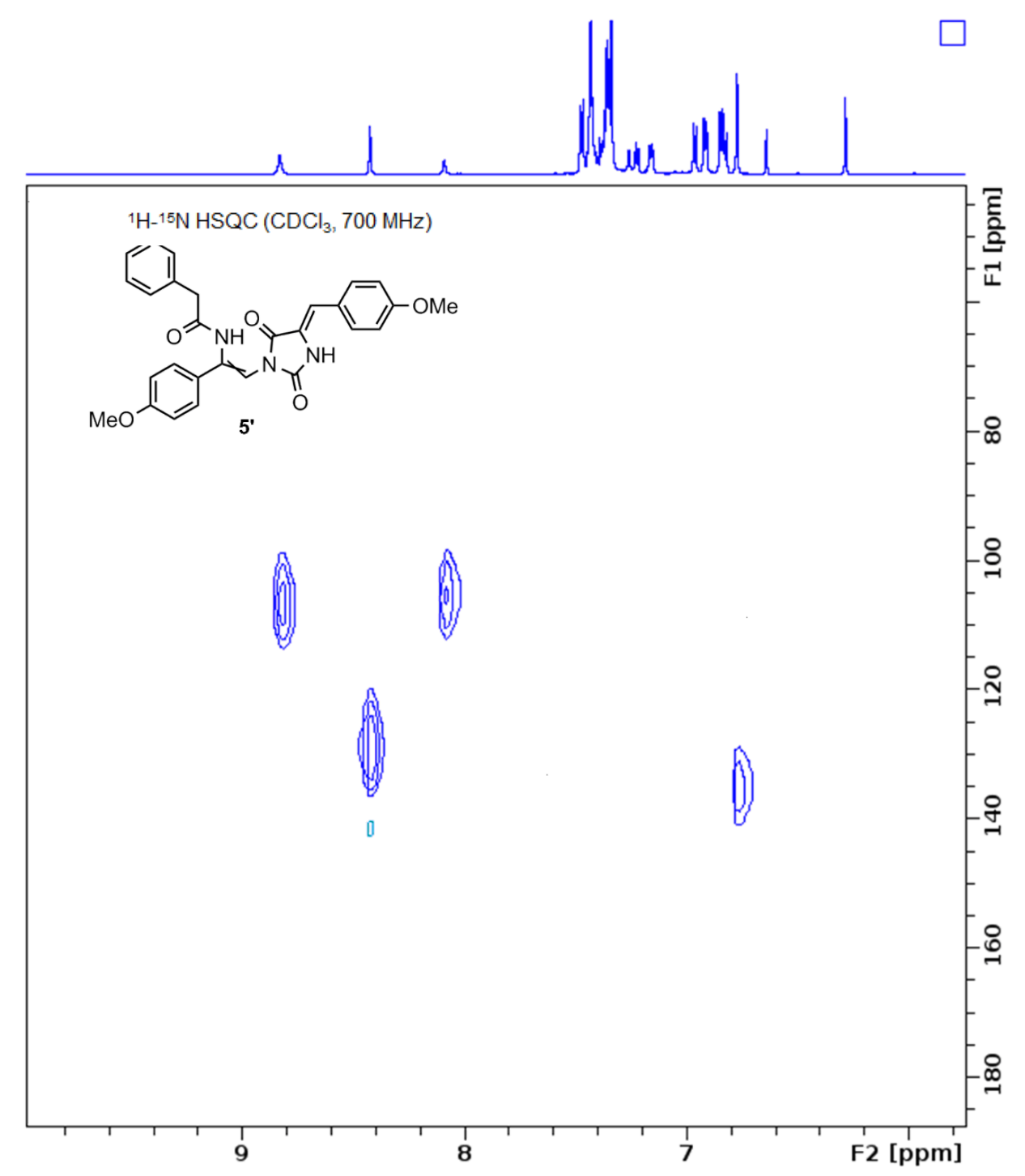

Figure S12. ${ }^{1} \mathrm{H}-{ }^{15} \mathrm{~N} \mathrm{HSQC} \mathrm{spectrum}(700 \mathrm{MHz})$ of $\mathbf{5}^{\prime}(Z+E)$ in $\mathrm{CDCl}_{3}$. 


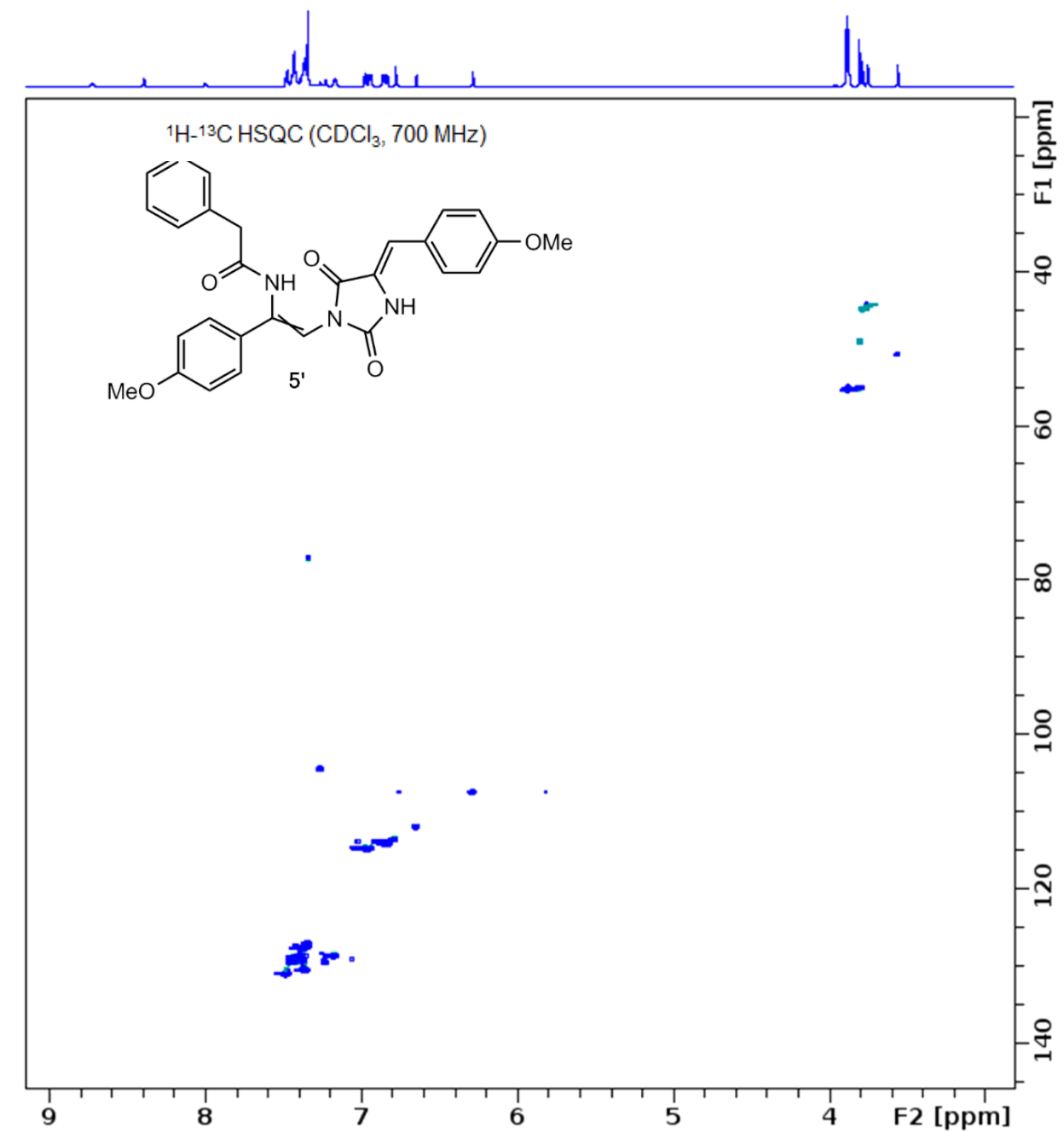

Figure S13. ${ }^{1} \mathrm{H}-{ }^{13} \mathrm{C}$ HSQC spectrum $(700 \mathrm{MHz})$ of $5^{\prime}(Z+E)$ in $\mathrm{CDCl}_{3}$. 


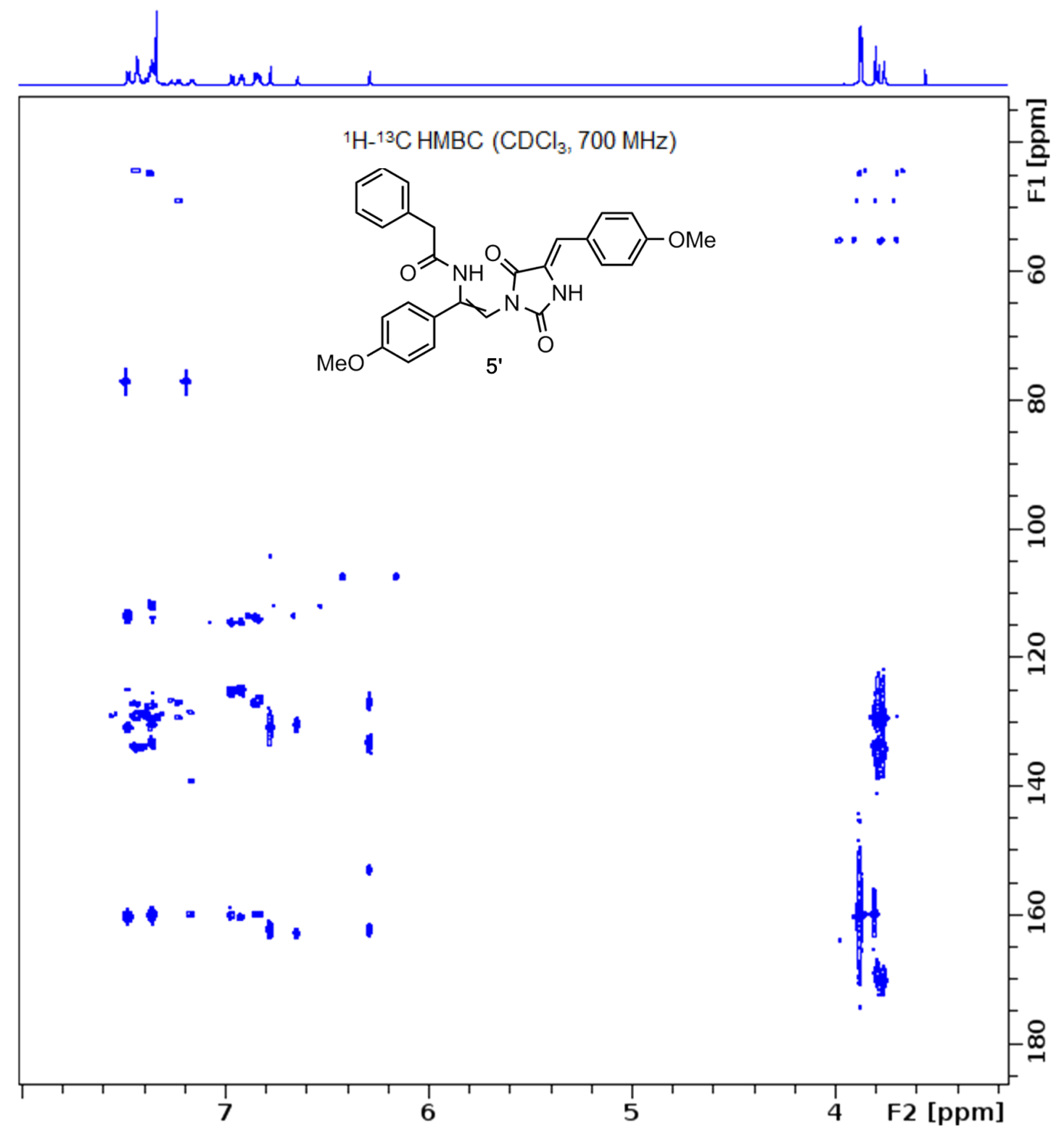

Figure S14. ${ }^{1} \mathrm{H}-{ }^{13} \mathrm{C} \mathrm{HMBC}(700 \mathrm{MHz})$ spectrum of $\mathbf{5}^{\prime}(Z+E)$ in $\mathrm{CDCl}_{3}$. 


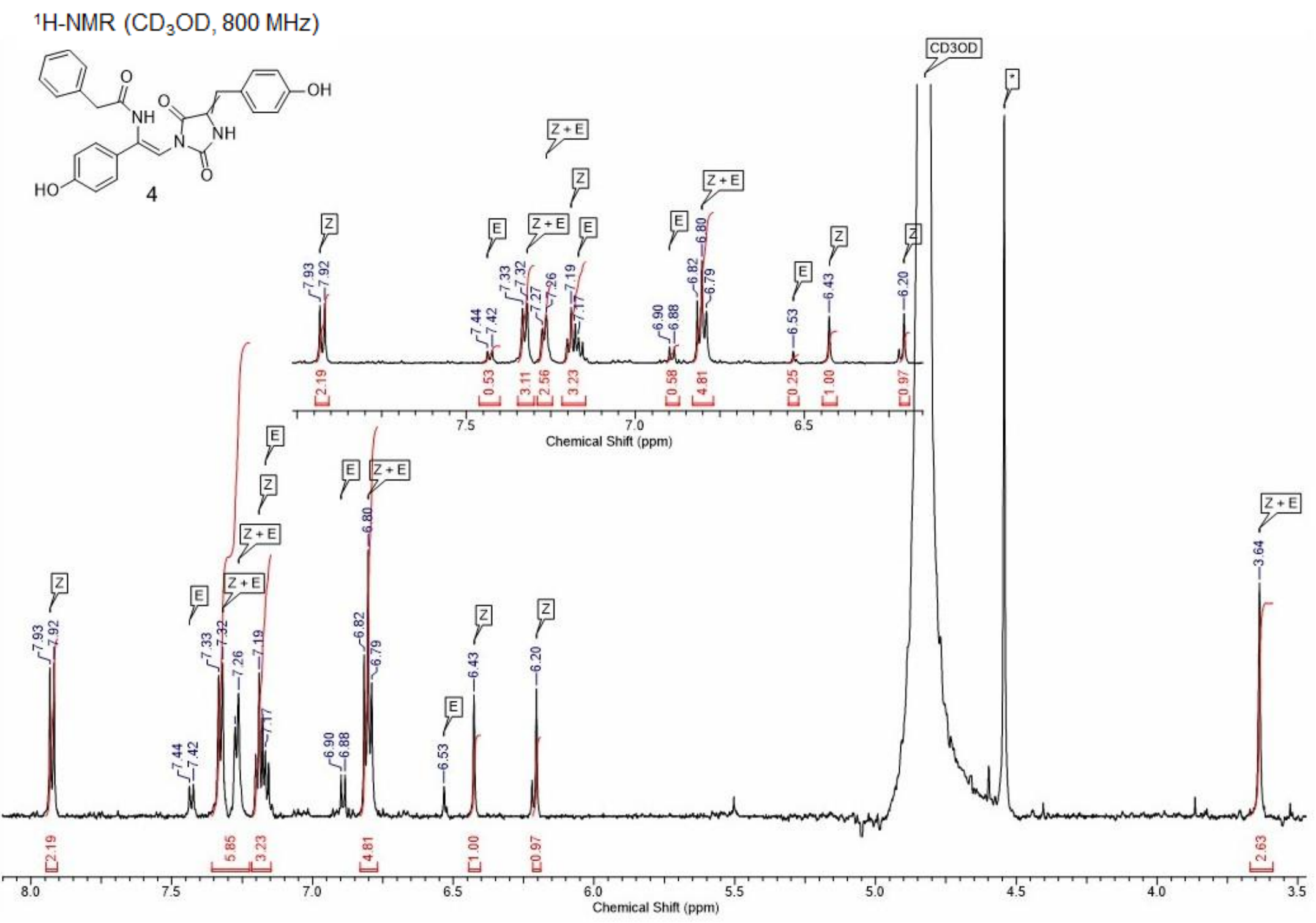

Figure S15. ${ }^{1} \mathrm{H}-\mathrm{NMR}$ spectrum $(800 \mathrm{MHz})$ of synthetic compound 4 (Z/E ratio 80/20) in $\mathrm{CD}_{3} \mathrm{OD}$. 


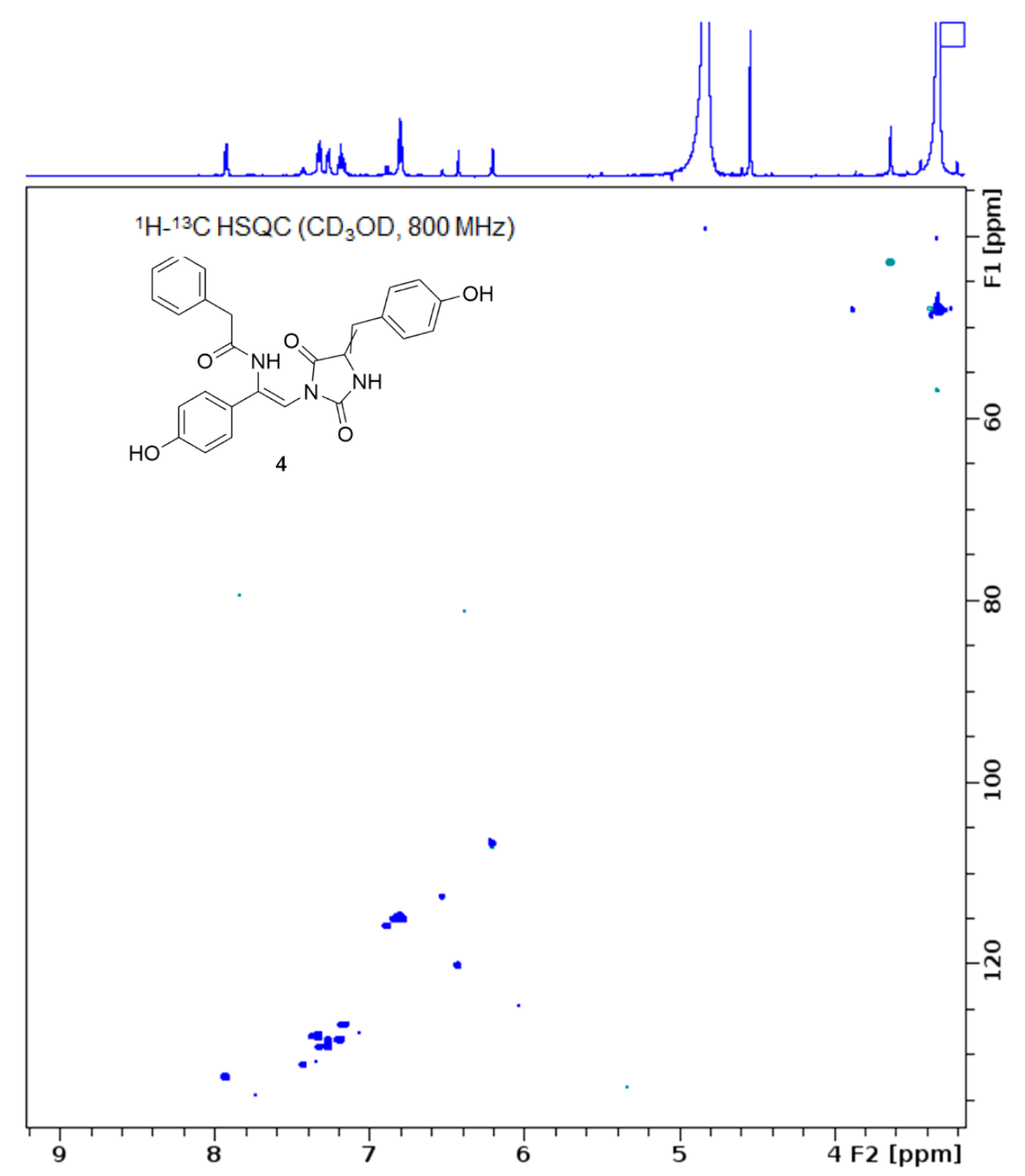

Figure S16. ${ }^{1} \mathrm{H}-{ }^{13} \mathrm{C} \mathrm{HSQC}$ spectrum $(800 \mathrm{MHz})$ of synthetic compound 4 (Z/E ratio 80/20) in $\mathrm{CD}_{3} \mathrm{OD}$. 


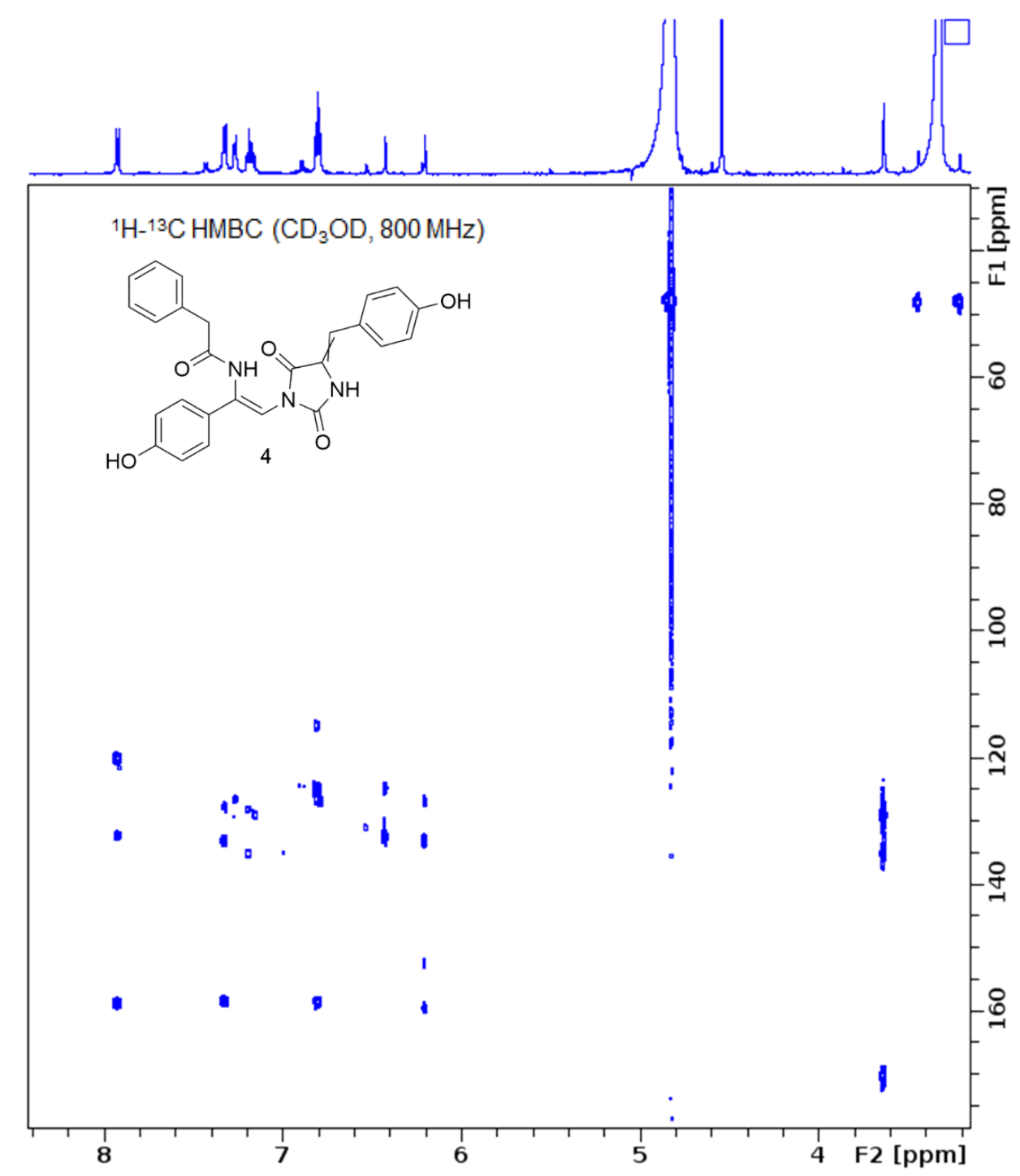

Figure S17. ${ }^{1} \mathrm{H}-{ }^{13} \mathrm{C} \mathrm{HMBC}$ spectrum $(800 \mathrm{MHz})$ of synthetic compound 4 (Z/E ratio 80/20) in $\mathrm{CD}_{3} \mathrm{OD}$. 


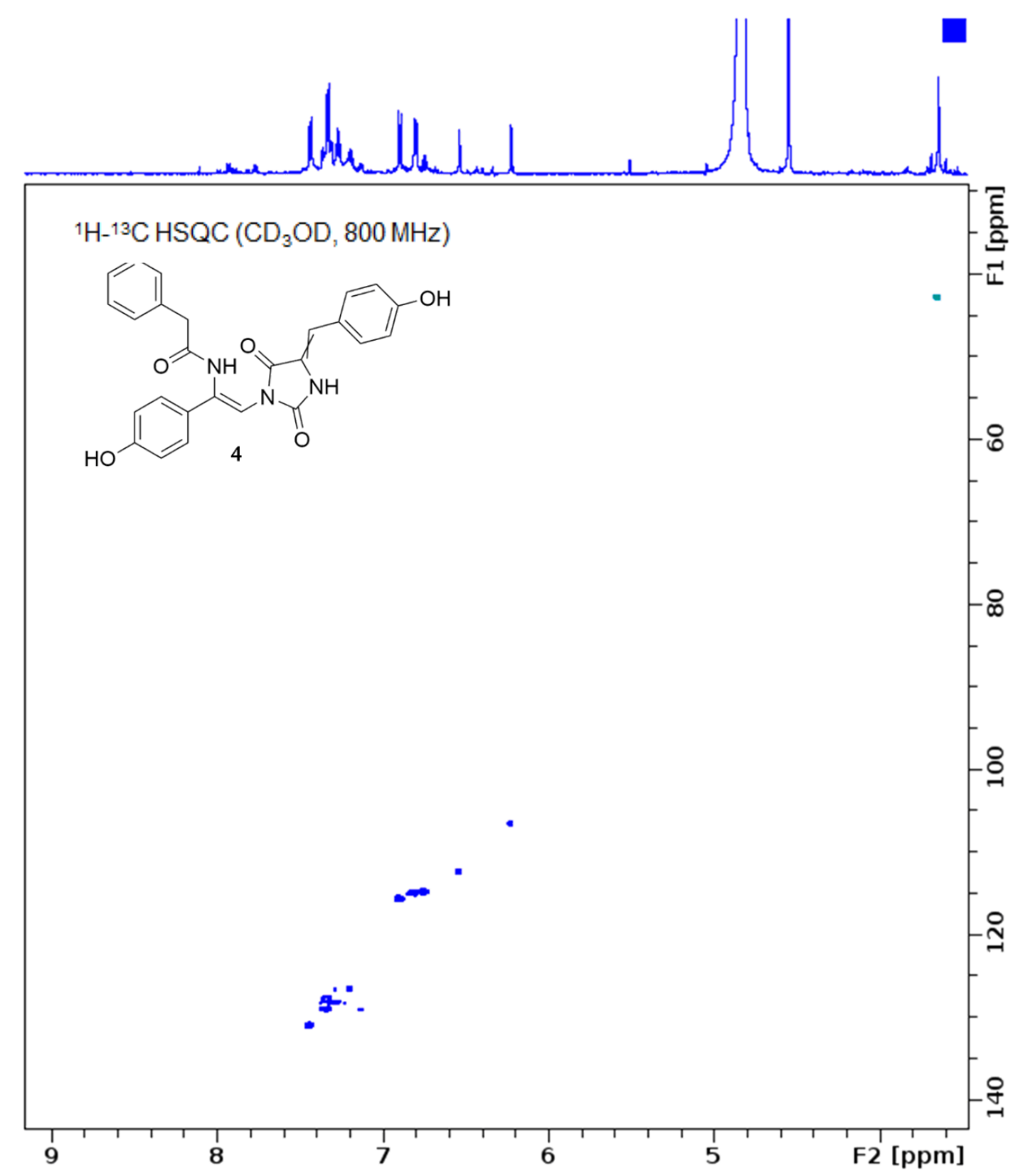

Figure S18. ${ }^{1} \mathrm{H}-{ }^{13} \mathrm{C}$ HSQC spectrum $\left(800 \mathrm{MHz}\right.$ ) of synthetic compound 4 (Z/E ratio 8/92) in $\mathrm{CD}_{3} \mathrm{OD}$. 


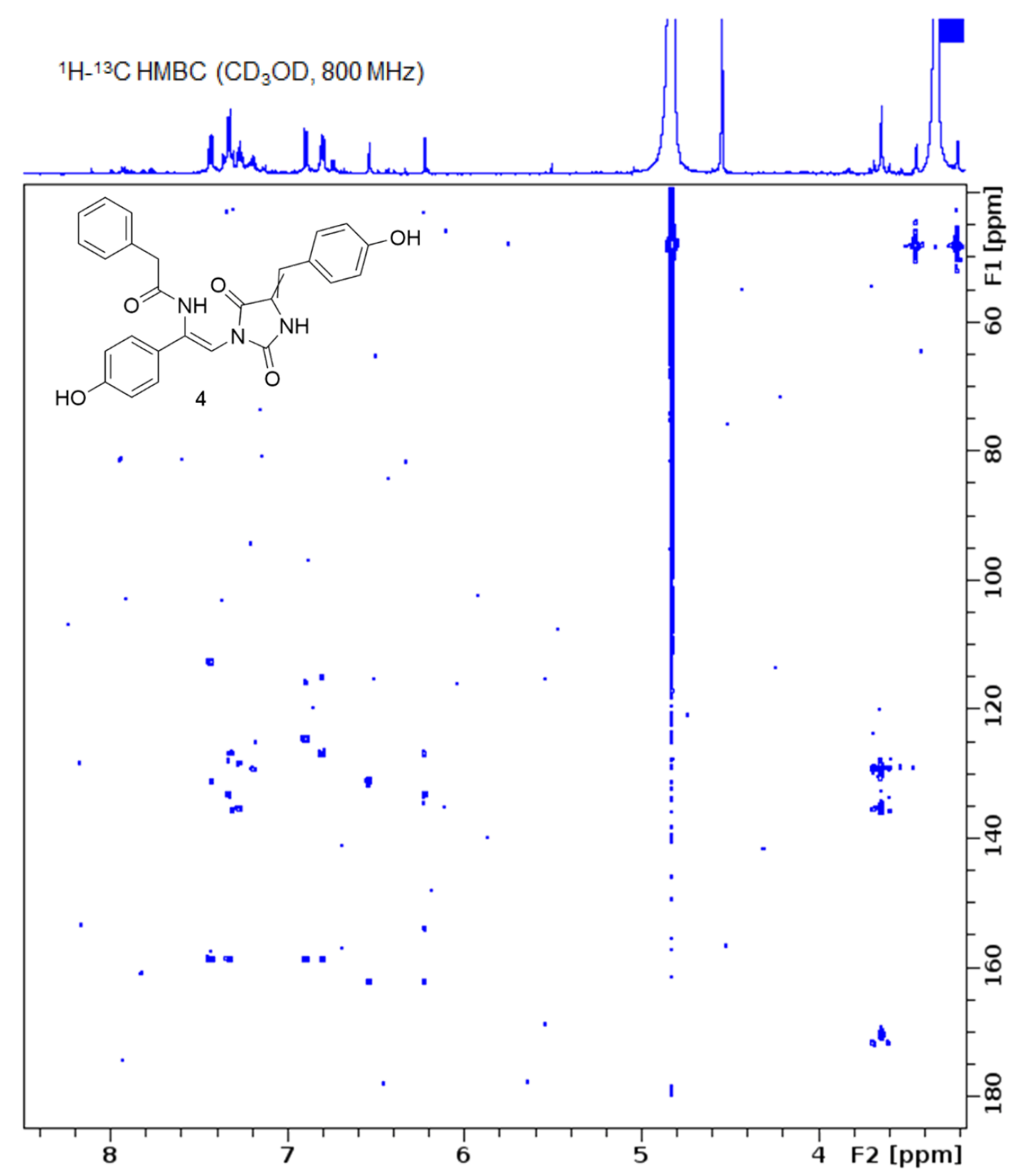

Figure S19. ${ }^{1} \mathrm{H}-{ }^{13} \mathrm{C}$ HMBC spectrum (800 MHz) of synthetic compound 4 (Z/E ratio 8/92) in $\mathrm{CD}_{3} \mathrm{OD}$. 


\section{Properties of compounds 4 ZIE}

Isomerization of $\mathbf{4}$ at r.t. The NMR sample of synthetic hydantoins $\mathbf{4} \mathbf{Z} / \mathbf{E}$ was kept at r.t. for 24 hours, then a series of NMR spectra were registered as described previously for the same sample. As a result, an isomerization of $5 \mathrm{C}-6 \mathrm{C}$ double bond was demonstrated: $Z / E$ ratio changed from $80 \%$ of $Z$ to $14 \%$ of $Z$.

${ }^{1} \mathrm{H}-\mathrm{NMR}\left(\mathrm{CD}_{3} \mathrm{OD}, 600 \mathrm{MHz}\right)$
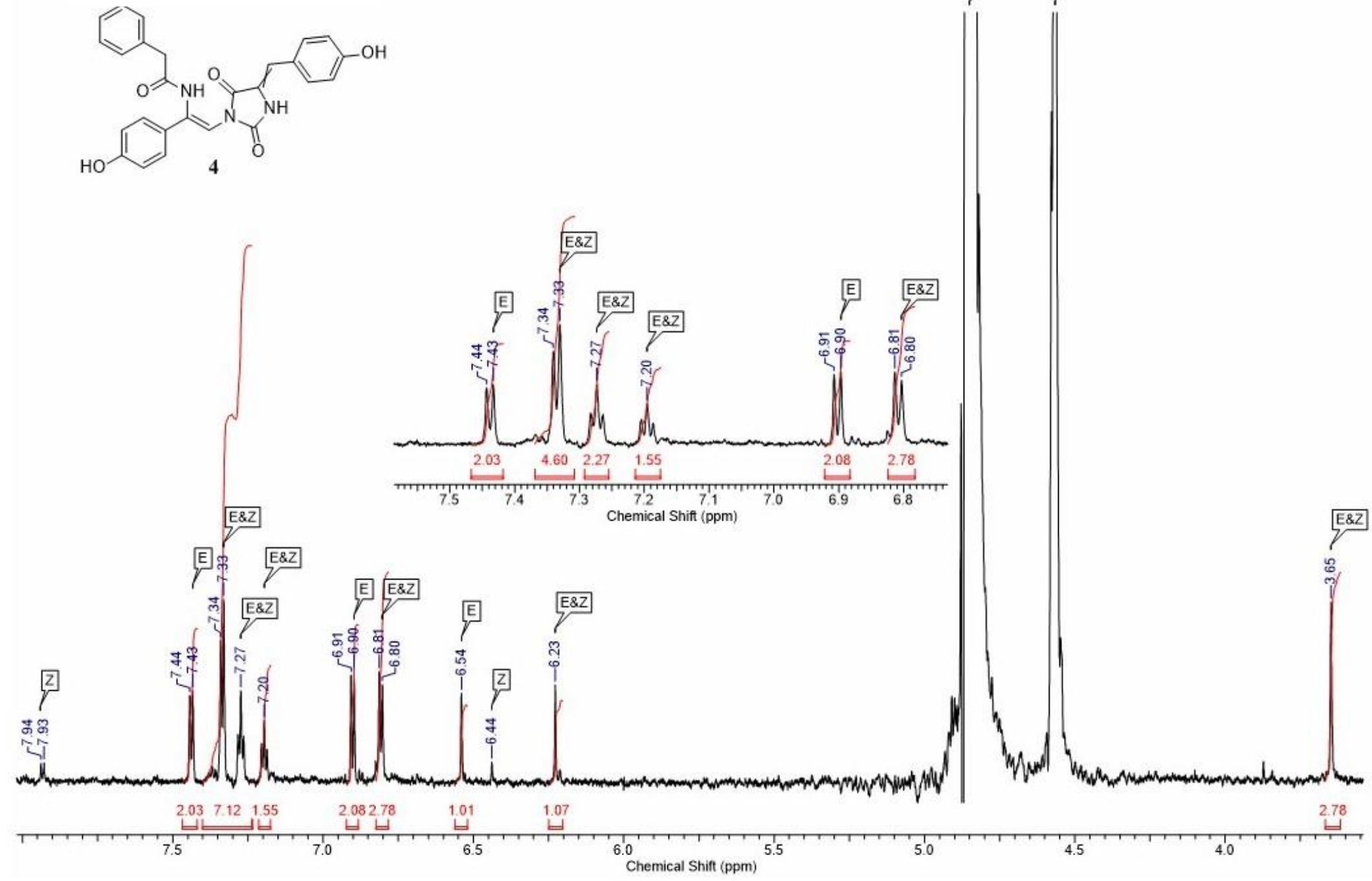

Figure S20. ${ }^{1} \mathrm{H}-\mathrm{NMR}$ spectrum $(600 \mathrm{MHz})$ of synthetic compound 4 after photoisomerization (Z/E ratio $\left.14 / 86\right)$ in $C D_{3} \mathrm{OD}$. 


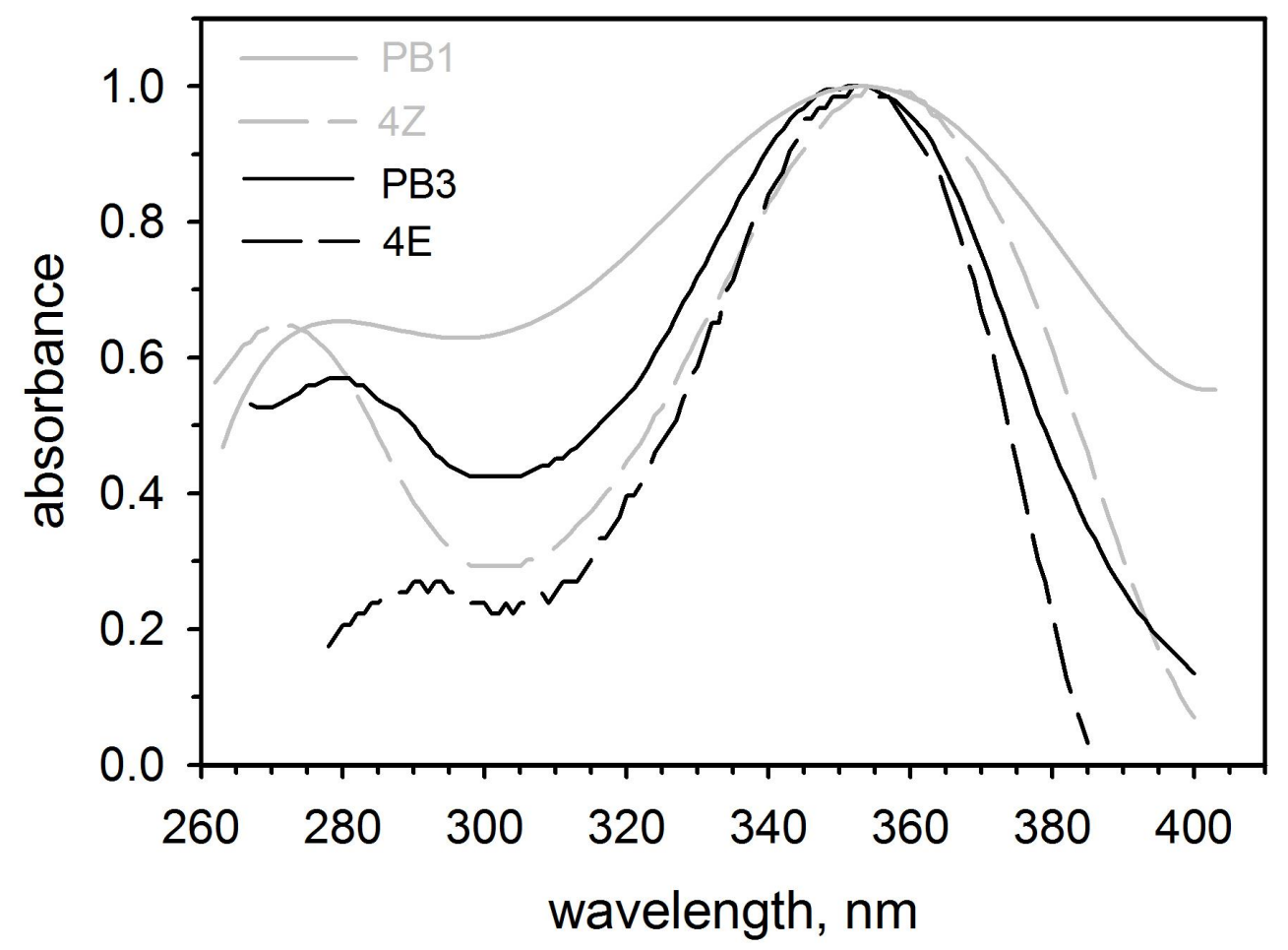

Figure S21. Comparison of absorbance spectra for synthetic compound 4 (isomers $Z$ and $E$ ) and compounds from fractions PB1/3. The measurements were performed in $50 \%$ acetonitrile and $0.05 \%$ formic acid aquatic solution at $r$. $t$. 